\title{
Multi-trait genome-wide association study of opioid addiction: OPRM1 and Beyond
}

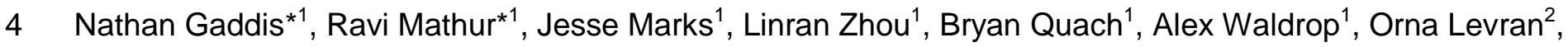
$5 \quad$ Arpana Agrawal ${ }^{3}$, Matthew Randesi ${ }^{2}$, Miriam Adelson ${ }^{4}$, Paul W. Jeffries $^{3}$, Emma C. Johnson ${ }^{3}$, Nicholas G.

6 Martin $^{5}$, Louisa Degenhardt ${ }^{6}$, Grant W Montgomery ${ }^{7}$, Leah Wetherill ${ }^{8}$, Dongbing Lai ${ }^{8}$, Kathleen Bucholz ${ }^{3}$,

7 Tatiana Foroud ${ }^{8}$, Bernice Porjesz ${ }^{9}$, Bradley Todd Webb ${ }^{1}$, Richard C. Crist ${ }^{10}$, Henry R. Kranzler ${ }^{10}$, Hang Zhou $^{11}$,

8 Gary Hulse $^{12}$, Dieter Wildenauer ${ }^{12}$, Erin Kelty ${ }^{13}$, John Attia ${ }^{14}$, Elizabeth G. Holliday ${ }^{14}$, Mark McEvoy ${ }^{14,15}$,

9 Rodney J. Scott ${ }^{16}$, Sibylle G Schwab ${ }^{17}$, Brion S. Maher ${ }^{18}$, Richard Gruza ${ }^{19}$, Mary-Jeanne Kreek ${ }^{2 * \star}$, Elliot C.

I0 Nelson ${ }^{3}$, Wade H. Berrettini ${ }^{11}$, Joel Gelernter ${ }^{20}$, Howard Edenberg ${ }^{21}$, Laura Bierut ${ }^{22}$ Dana B. Hancock $^{1}$, Eric O.

11 Johnson*+1,23

I3 ${ }^{1}$ GenOmics, Bioinformatics, and Translational Research Center, Biostatistics and Epidemiology Division, RTI

I4 International, Research Triangle Park, NC

I5 2 The Laboratory of the Biology of Addictive Diseases, The Rockefeller University, New York, NY

I6 ${ }^{3}$ Department of Psychiatry, Washington University School of Medicine, St. Louis, MO

$17{ }^{4}$ Dr. Miriam and Sheldon G. Adelson Clinic for Drug Abuse, Treatment and Research, Las Vegas, NV

I8 ${ }^{5}$ Genetic Epidemiology, QIMR Berghofer Medical Research Institute, Brisbane, Australia

I9 National Drug and Alcohol Research Centre, University of New South Wales, Randwick, NSW, Australia

?0 $\quad{ }^{7}$ Institute for Molecular Bioscience, The University of Queensland, Brisbane, QLD, Australia

?1 $\quad{ }^{8}$ Medical and Molecular Genetics, Indiana University School of Medicine, Indianapolis, IN

?2 ${ }^{9}$ Department of Psychiatry, State University of New York Downstate Medical Center, Brooklyn, NY

?3 $\quad{ }^{10}$ Department of Psychiatry, University of Pennsylvania, Philadelphia, PA

?4 $\quad{ }^{11}$ Department of Psychiatry, Yale University School of Medicine, West Haven, CT 
$25{ }^{12}$ School of Psychiatry and Clinical Neurosciences, The University of Western Australia, Perth, WA, Australia

?6 ${ }^{13}$ School of Population and Global Health, Population and Public Health, The University of Western Australia, $? 7$ Perth, WA, Australia

$28{ }^{14}$ Public Health College of Health, Medicine and Wellbeing, The University of Newcastle, New Lambton

29 Heights, NSW, Australia

$30{ }^{15}$ School of Medicine, The University of Newcastle, New Lambton Heights, NSW, Australia

$31{ }^{16}$ School of Biomedical Sciences and Pharmacy College of Health, Medicine and Wellbeing, The University of

32 Newcastle, New Lambton Heights, NSW, Australia

$33{ }^{17}$ Faculty of Science, Medicine and Health, University of Wollongong, Wollongong, NSW, Australia

$34{ }^{18}$ Department of Mental Health, Bloomberg School of Public Health, Johns Hopkins University, Baltimore, MD

$35{ }^{19}$ Department of Family and Community Medicine, Saint Louis University, Saint Louis, MO

$36{ }^{20}$ Department of Psychiatry, Genetics, \& Neuroscience, Yale University School of Medicine, West Haven, CT

$37 \quad{ }^{21}$ Biochemistry and Molecular Biology, Indiana University School of Medicine, Indianapolis, IN

$38 \quad{ }^{22}$ Department of Psychiatry, Washington University, St. Louis, MO

$39{ }^{23}$ Fellow Program, RTI International, Research Triangle Park, NC

$11 \quad$ * Authors contributed equally to this manuscript

t2 + Corresponding Author

13 ** Recently deceased. 


\section{Abstract}

15 Opioid addiction $(\mathrm{OA})$ has strong heritability, yet few genetic variant associations have been robustly identified.

16 Only rs1799971, the A118G variant in OPRM1, has been identified as a genome-wide significant association 17 with $\mathrm{OA}$ and independently replicated. We applied genomic structural equation modeling to conduct a GWAS 18 of the new Genetics of Opioid Addiction Consortium (GENOA) data and published studies (Psychiatric 19 Genomics Consortium, Million Veteran Program, and Partners Health), comprising 23,367 cases and effective j0 sample size of 88,114 individuals of European ancestry. Genetic correlations among the various OA 51 phenotypes were uniformly high $\left(r_{g}>0.9\right)$. We observed the strongest evidence to date for OPRM1: lead SNP j2 rs9478500 $\left(p=2.56 \times 10^{-9}\right)$. Gene-based analyses identified novel genome-wide significant associations with j3 PPP6C and FURIN. Variants within these loci appear to be pleiotropic for addiction and related traits. 
medRxiv preprint doi: https://doi.org/10.1101/2021.09.13.21263503; this version posted September 16, 2021. The copyright holder for this preprint (which was not certified by peer review) is the author/funder, who has granted medRxiv a license to display the preprint in perpetuity.

It is made available under a CC-BY-NC-ND 4.0 International license .

In 2020 the U.S. saw the highest 12-month count of opioid overdose deaths recorded, $>70,000^{1}$, which represents a $40 \%$ increase since 2019 , a $>250 \%$ increase since $2000,{ }^{2}$ and is 1.7 times the number of deaths caused by automobile crashes in $2020 .^{3}$ Approximately $4 \%$ of the U.S. population aged 12 and older (10.1 million people) misused opioids in 2019, with 1.6 million people initiating new prescription opioid misuse. ${ }^{4}$ The most recent annual estimate of the total economic burden of prescription opioid abuse and dependence in the U.S. (2013) is over $\$ 78$ billion, ${ }^{5}$ including Medicaid spending of more than $\$ 8$ billion on opioid addiction (OA) treatment. ${ }^{6}$ By every metric, the opioid epidemic continues to be a tremendous burden, and the need to expand the medication-assisted treatment toolkit for OA through identification of new targets for drug development is clear. ${ }^{7}$

Animal model and human neuroimaging studies have established a strong, albeit partial, understanding of the neurocircuitry of addiction as heuristically characterized in the Koob and Volkow model. ${ }^{8}$ The primary neurocircuitry elements involved (basal ganglia, extended amygdala, and prefrontal cortex) and their molecular connections to the cycle of addiction (intoxication, withdrawal, and preoccupation) are broadly understood. However, there is clear variability in the functioning of this neurocircuitry among individuals as evidenced by only $20-30 \%$ of people who use heroin becoming addicted ${ }^{9,10}$ and only $8-12 \%$ of chronic pain patients prescribed opioids developing OA. ${ }^{11}$

Genetics is a major contributor to individual variation in the risk of developing OA, with $\sim 60 \%$ of the population variability being attributable to genetic factors. ${ }^{12,13}$ This heritability estimate is comparable to other complex phenotypes, such as Alzheimer's, ${ }^{14}$ age-related macular degeneration, ${ }^{15}$ and height, ${ }^{16}$ which have conclusively associated genetic variants. However, few robust genetic variant associations with OA have been identified. ${ }^{17-20}$

Eight genome-wide association studies (GWAS) of OA have been reported, ${ }^{21-28}$ in which the number of cases varied from 104 to 10,544 for ancestry specific analyses. Six of these GWAS identified genome-wide significant loci. ${ }^{23,25-29}$ However, only the largest analysis, which combined results of European ancestry (EA) 
medRxiv preprint doi: https://doi.org/10.1101/2021.09.13.21263503; this version posted September 16, 2021. The copyright holder for this

preprint (which was not certified by peer review) is the author/funder, who has granted medRxiv a license to display the preprint in perpetuity.

It is made available under a CC-BY-NC-ND 4.0 International license .

30 cohorts from the US Veterans Affairs Million Veterans Program (MVP), the Study of Addiction: Genetics and

31 Environment (SAGE), and Yale-Penn (YP) cohorts (10,544 cases and 72,163 controls), identified a genome-

32 wide significant association that replicated in an independent sample (additional YP data: 508 cases and 206

33 controls). The variant identified is the long-studied rs1799971 (OPRM1-A118G), a functional coding variant

34 (encoding Asn40Asp) in the mu opioid receptor gene (OPRM1): discovery $p=1.51 \times 10^{-8}$, replication $p=0.049$.

35 The rs1799971-G protective association with OA was also extended at nominal significance to buprenorphine treatment status in the UK Biobank (240 cases and 360901 controls; $p=0.04$ ).

To maximize discovery, we leveraged genomic structural equation modeling (gSEM) ${ }^{30}$ to combine new and existing GWAS with varied, but closely related, phenotypes for OA to enable the largest GWAS of OA to date $(23,367$ cases, 384,629 controls: effective sample size 88,114$)$. We brought together novel results from the Genetics of Opioid Addiction Consortium (GENOA) with publicly available summary statistics from the MVP-SAGE-YP, ${ }^{27}$ the Psychiatric Genetics Consortium - Substance Use Disorder Group (PGC-SUD), ${ }^{26}$ and the Partners Health Group $(\mathrm{PH}) .{ }^{28}$ We examined SNP-based heritability and genetic correlation among the varied phenotypic definitions of OA across the contributing cohorts, including diagnostic and frequency of usebased cases and different types of controls: opioid exposed, unexposed, and population-based. We conducted a variant level gSEM analysis in the full complement of cohorts and a gene-based association test based on those results. gSEM accounts for the sample overlap among the GENOA, PGC-SUD, and MVP-SAGE-YP analyses, therefore increasing the available sample size compared to standard meta-analysis. Follow-up analyses included: (1) evaluation of genetic correlation with brain-related phenotypes; (2) estimation of predicted genetically driven differential expression in brain tissues; (3) colocalization of genetic association loci with cis-eQTLs; (4) evaluation of loci pleiotropy, and (5) druggability of nominated targets.

This study provides an unequivocal genome-wide significant association signal for the intron 1 locus in OPRM1 and, through haplotype analysis, suggests that rs1799971 (A118G) may not be the driver of the 
medRxiv preprint doi: https://doi.org/10.1101/2021.09.13.21263503; this version posted September 16, 2021. The copyright holder for this preprint (which was not certified by peer review) is the author/funder, who has granted medRxiv a license to display the preprint in perpetuity. It is made available under a CC-BY-NC-ND 4.0 International license .

)4 with OA: PPP6C and FURIN. Both genes have been previously associated with phenotypes correlated with OA

)5 (e.g. PPP6C with cigarette smoking, ${ }^{31,32}$ alcohol consumption, ${ }^{31}$ and depressive symptoms ${ }^{33}$ FURIN with

6 schizophrenia, ${ }^{34,35}$ risk tolerance, ${ }^{36}$ and insomnia $\left.{ }^{36}\right)$. This study links these genes to predicted genetically

)7 driven differential expression in brain tissues by OA. Colocalization analysis supports a shared single variant

8 between $O A$ association and gene expression for PPP6C but provides less clear results for OPRM1 and

)9 FURIN. Collectively, these results provide extended insight into the association of OPRM1 with OA as well as

I0 novel genes associated with this phenotype. 
medRxiv preprint doi: https://doi.org/10.1101/2021.09.13.21263503; this version posted September 16, 2021. The copyright holder for this

preprint (which was not certified by peer review) is the author/funder, who has granted medRxiv a license to display the preprint in perpetuity.

It is made available under a CC-BY-NC-ND 4.0 International license .

I1 Results

12 Different approaches to defining OA are highly genetically correlated. Our gSEM for OA brings together I3 novel GWAS data from GENOA and summary statistics from all prior GWAS of OA that included more than 141,000 cases and 1,000 controls of European ancestry (EA). ${ }^{26-28}$ GENOA is a new consortium comprised of investigators who attend the National Institute on Drug Abuse Genetics and Epigenetics Cross-cutting Research Team Meetings and who have GWAS data on OA (Supplementary Table 1). In this study, OA refers to a broad meaning of addiction to opioids defined by multiple approaches to measuring the phenotype. The success of both the GENOA and gSEM analyses to maximize sample size and discovery then depends on similar heritability and high genetic correlations across the different measures of $O A$.

We focused on EA cohorts for the genetic correlation and gSEM analyses because these approaches, which allow us to maximize sample size by bridging phenotypes and accounting for cohort overlap, require linkage disequilibrium score regression (LDSC) results to model the genetic variance-covariance matrix. LDSC in turn depends on an ancestry-specific reference panel, which isn't currently available for African Americans (AAs).

Among the 9 independent EA cohorts contributing to GENOA, OA was defined by Diagnostic and Statistical Manual criteria for opioid abuse or dependence (DSM-based; $N=17,061$ ) or by frequency of use (FOU) of illicit opioids (e.g., injecting heroin 10 or more times in the past 30 days; FOU-based; $N=11,976$; Supplementary Table 1). SNP-based heritability for both phenotypes was strong (DSM-based: $h^{2}=0.11$, $S E=0.03$; FOU-based: $\left.h^{2}=0.18, S E=0.04\right)$ and their genetic correlation robust $\left(r_{g}=1.05, S E=0.16\right.$; SNP-based genetic correlations are not bound by 1.0).

Across the full set of GWAS results contributing to the gSEM GWAS (i.e., GENOA, MVP-SAGE-YP, PGC-SUD, and PH) there are additional OA definitions (MVP and PH used Electronic Health Record ICD-9 or

ICD-10 codes for opioid use disorder [OUD]) and variation in type of controls used. GENOA cohorts used a combination of controls (opioid exposed, unexposed, and unknown exposure population controls). MVP and 
35 PH used opioid exposed controls, and the PGC-SUD results used here were based on unexposed controls.

36 Regardless of the approach to defining OA or the type of controls, the LDSC genetic correlations across

37 cohorts were very high (all pairwise $r_{g}>0.9$, Supplementary Table 2). These heritabilities and genetic correlations show that the genetics contributing to OA are highly shared regardless of OA case definition or opioid exposure status of controls to which the cases are compared.

H1 GENOA GWAS identifies one European Ancestry specific OA association. Conducting ancestry specific and cross-ancestry meta-analyses of the GENOA cohorts (Supplementary Figures 1-6 and Supplementary

13 Tables 3-5) yielded one genome-wide significant association locus on chromosome 4 among EAs

$14 \quad\left(\right.$ rs28386916-A, beta $\left.=0.17, p=9.04 \times 10^{-9}\right)$. The $r s 28386916$ variant was not associated with OA among AAs 15 (beta $=-0.025, p=0.51$ ) and consequently was no longer significant in the $E A+A A$ meta-analysis. $r s 28386916$ t6 is an intronic variant located within the long noncoding RNA ENST00000659878 and between the SNCA and 17 GPRIN3 genes (Supplementary Figure 7). Although, rs28386916-A is common (EUR MAF = 0.40; AFR MAF = t8 0.81 ) and was well imputed (imputation quality $>0.8$ across cohorts), this variant is not available in the results 19 from the independent MVP or PH GWAS. 
medRxiv preprint doi: https://doi.org/10.1101/2021.09.13.21263503; this version posted September 16, 2021. The copyright holder for this preprint (which was not certified by peer review) is the author/funder, who has granted medRxiv a license to display the preprint in perpetuity.

It is made available under a CC-BY-NC-ND 4.0 International license .

\section{Genomic Structural Equation Model GWAS of Opioid Addiction identifies two other genome-wide} significant loci in European Ancestry. A single common factor gSEM (Figure 1a) fit the GENOA, MVPSAGE-YP, PGC-SUD, and PH summary statistics for OA well, with high Akaike information criterion and comparative fit index, and low standardized root mean squared root (SRMR) values (Figure 1a). Testing the association of 2.4 million variants available across all cohorts with the latent genetic factor (effective sample size $N=88,114$ ) identified two genome-wide significant loci (Figure 1b; Q-Q plot Supplementary Figure 8): one with 32 genome-wide significant variants (top variant rs9478500-C, beta $=0.136, p=2.56 \times 10^{-9}$; Supplementary Table 6; forest plot Supplementary Figure 9a) on chromosome 6 and the other represented by a single variant on chromosome 16 ( $r$ 13333582-C, beta $=-0.219, p=3.58 \times 10^{-8}$; forest plot Supplementary Figure 10). The LDSC intercept for this model (Figure 1b), being approximately 1 , indicates that these results are not due to uncontrolled inflation that one would expect from inadequately accounting for overlap in the cohorts contributing to some of the summary statistics used here. ${ }^{30}$

The associated locus on chromosome 6 was centered in intron 1 of the mu-opioid receptor gene OPRM1 (Supplementary Figure 11). The minor allele of the lead variant, rs9478500-C, was associated with increased risk of $O A$ (beta $=0.136$ ). All of the genome-wide significant variants were in high linkage disequilibrium (LD) with each other $\left(r^{2}>0.88\right.$ and D'>0.93; Supplementary Table 7). The previously reported missense variant rs1799971 (OPRM1-A118G), which was genome-wide significant for OUD in MVP-SAGE-YP ${ }^{27}$, was less statistically significant in our gSEM analysis ( $r$ 1799971-G, beta $=-0.115, p=1.94 \times 10^{-6}$; forest plot Supplementary Figure 9b). This variant has low $r^{2}(<0.04)$, but perfect D' (1.0), with the genome-wide significant variants observed here. In the MVP GWAS rs9478500-C was associated with OA, but with less statistical significance (MVP rs9478500-C, beta $=0.09, p=4.31 \times 10^{-5}$ ). Prior candidate gene studies that examined OPRM1 haplotypes with rs1799971 suggested that other variants may explain its equivocal association with OA. ${ }^{37,38}$ Raw data for haplotype analysis was available from a subset of cohorts contributing to the gSEM analysis (Figure 2). In this subset of cohorts, the single variant results for rs 1799971 were weaker 
75 than in the $\mathrm{gSEM}$ (beta=-0.058, $p=0.135$ ) and slightly stronger for rs9478500 (beta=0.205, $\left.p=2.43 \times 10^{-9}\right)$.

'6 Comparison of the three haplotypes formed by rs1799971 and the genome-wide significant variants (Figure

77 2a) further weakened evidence for an association with OA being driven by rs 1799971 (Figure 2b comparison 1:

$78 p=0.52$, beta $=-0.026, \mathrm{SE}=0.0397)$ and strengthened evidence for an association with $\mathrm{OA}$ being driven by the

79 effect of the non-rs1799971 variants (comparison 2: $p=1.63 \times 10^{-10}$, beta $=0.2303, \mathrm{SE}=0.036$, Figure $2 b$ ).

The genome-wide significant rs 13333582 variant on chromosome 16 is intergenic (Supplementary

Figure 9): rs $13333582-\mathrm{C}$ minor allele (frequency $=0.04$, imputation quality $>0.8$ for all cohorts) being

associated with decreased risk of $O A$ (beta $=-0.22$ ). However, the variants with which rs 13333582 has strong

LD showed weak evidence for association with OA (e.g., rs921982 $r^{2}=0.87, p=2.25 \times 10^{-3}$ ).

OA is genetically correlated with 21 other brain-related traits. We used LDSC to estimate the genetic

correlation between OA (gSEM results) and 37 brain related traits (Figure 3, Supplementary Table 8); of these,

21 were significantly correlated with $\mathrm{OA}$ at the Bonferroni corrected threshold of $p<1.35 \times 10^{-3}$. We observed

high positive genetic correlations for OA with cannabis use disorder and alcohol dependence, as well as

modest positive correlations across smoking traits and psychiatric disorders. Expected inverse genetic

correlations were also evident for age of initiation of cigarette smoking and cognitive/educational traits. There were no genetic correlations between $\mathrm{OA}$ and brain volume traits.

\section{Gene-based MAGMA GWAS of gSEM summary statistics for OA corroborates OPRM1 and identifies}

novel genes. To enhance statistical power for discovery, we analyzed the summary statistics from the gSEM

GWAS at the gene level using MAGMA ${ }^{39}$. In addition to OPRM1, we observed two novel genes associated with OA that surpassed Bonferroni correction for the 15,977 genes tested ( $p<3.13 \times 10^{-6}$; Figure 4; Q-Q plot 
medRxiv preprint doi: https://doi.org/10.1101/2021.09.13.21263503; this version posted September 16, 2021. The copyright holder for this preprint (which was not certified by peer review) is the author/funder, who has granted medRxiv a license to display the preprint in perpetuity.

It is made available under a CC-BY-NC-ND 4.0 International license .

The gene-level association between the Protein Phosphatase 6 Catalytic subunit gene (PPP6C) and OA was based on 57 variants and corresponds to the variant-level peak that approached genome-wide significance on chromosome 9 (Figure 1b). This peak encompassed PPP6C but variants in high LD and with moderate $p$-values for association with OA $\left(p=3.37 \times 10^{-7}\right.$ to $\left.2.14 \times 10^{-5}\right)$ extended across three genes: PPP6C, the Suppressor of Cancer Cell Invasion gene [SCAI], and the Rab9 Effector Protein with Kelch Motifs gene [RABEPK] (Supplementary Figure 14). However, SCAI and RABEPK associations with OA did not surpass Bonferroni correction ( $S C A / p=0.0016$; RABEPK $p=2.82 \times 10^{-5}$ )

The gene-level association for the Furin Paired Basic Amino Acid Cleaving Enzyme gene (FURIM) and OA was based on a single variant $\left(\mathrm{rs} 17514846-\mathrm{A}\right.$, beta $\left.=-0.08, p=8.82 \times 10^{-7}\right)$. Other FURIN variants were excluded from the gSEM GWAS, and thereby the MAGMA analysis, due to the gSEM method's requirement that variants be present in every contributing cohort. By running a standard logistic regression meta-analysis of FURIN variants across the subset of GWAS cohorts without overlapping participants (GENOA, MVP, and PH), we were able to retain additional variants excluded from the gSEM analysis, and identified 3 additional variants in strong LD with $r s 17514846\left(r^{2}>0.64, D^{\prime}=1.0\right)$; all four variants were associated with OA (Supplementary Figure 15; Supplementary Table 10), the weakest association being for $r s 17514846\left(p=1.67 \times 10^{-6}\right)$ and the strongest being for rs11372849, which was genome-wide significant (rs11372849-TC, beta $=-0.074$, $p=4.11 \times 10^{-8}$; forest plot Supplementary Figure 16).

\section{Predicted genetically driven gene expression in brain tissue expands neurobiologically relevant}

evidence for OA-associated genes. To estimate genetically driven differential gene expression in human brain tissues associated with OA, we applied S-PrediXcan ${ }^{40}$ using GTEx version 8 eQTL gene models (http://predictdb.org/) with the gSEM GWAS summary statistics as input. Fourteen gene-tissue combinations surpassed correction for the total number of gene models and brain tissues $(156,215$ tests) with an FDR $<0.05$ (Table 1; all results presented in Supplementary Table 11). Predicted genetically driven OPRM1 expression 
medRxiv preprint doi: https://doi.org/10.1101/2021.09.13.21263503; this version posted September 16, 2021. The copyright holder for this

preprint (which was not certified by peer review) is the author/funder, who has granted medRxiv a license to display the preprint in perpetuity.

It is made available under a CC-BY-NC-ND 4.0 International license .

was significantly associated with OA in cerebellum. Only four brain tissues had gene models for OPRM1 (cerebellum, cerebellar hemisphere, hypothalamus, and nucleus accumbens; Supplementary Table 11). In contrast, 12 brain tissues had gene models for PPP6C; of these, $P P P 6 C$ was predicted to be differentially expressed in nine tissues. Nearby SCA/ was the only other gene to show statistically significant genetically driven expression associated with $\mathrm{OA}$, doing so across four brain tissues. FURIN was nominally associated (best $p=9.67 \times 10^{-5}$ in hippocampus) but did not surpass the FDR $<0.05$ threshold. $R A B E P K$ was not predicted to be differentially expressed by OA (best $p=0.055$ in caudate).

Some OA associations colocalize with genetically driven gene expression. To estimate the likelihood that the genetic loci associated with OA share a causal variant with the expression quantitative trait loci (eQTLs) for our nominated genes (OPRM1, PPP6C, and FURIN), we applied coloc ${ }^{41}$ to our gSEM GWAS results and the GTEx eQTL results for these genes. Because the variants underlying the genome-wide significant association for PPP6C physically extend into SCAI and RABEPK (Supplementary Figure 14), we included these genes in the analysis. We evaluated colocalization for these genes across the superset of 10 brain tissues which showed genetically driving differential expression for at least one gene in the S-PrediXcan analysis (Supplementary Table 11). OPRM1 is expressed at relatively low levels in the GTEx brain tissues (Supplementary Figure 17a). Only six of 10 brain tissues showed variant associations with OPRM1 expression in GTEx and could be included in the coloc analysis. The posterior probabilities for four tissues of the six tissues tested for OPRM1 favored the hypothesis that only a genetic association with OA at this locus is present (Figure $5 \mathrm{H} 2$, Supplementary Table 12). However, in the cerebellum, where OPRM1 is most highly expressed and for which S-PrediXcan predicted differential expression by OA, the greatest posterior probabilities favored hypotheses for both the OA-associated locus and cis-eQTL traits being associated, but with different causal variants $(\mathrm{H} 3)$ or a shared single causal variant $(\mathrm{H} 4)$. Among the three genes at the PPP6C-centered locus, PPP6C shows the highest levels of gene expression in brain tissues (Supplementary 
t6 Figure $17 \mathrm{~b}-\mathrm{d}$ ) and the greatest support for colocalization of OA-associated variants with cis-eQTLs for PPP6C

17 (Figure 5, Supplementary Table 12). In contrast, the analysis for RABEPK uniformly indicated that the OA-

18 associated variants do not colocalize with the RABEPK cis-eQTLs. For FURIN, the null hypothesis of neither

19 trait being associated in this region has the highest posterior probability across all tested brain tissues (Figure

j0 5, Supplementary Table 12), which is consistent with (1) a single variant ( $r$ 17514846) driving the genome-

¡1 wide significant gene-based association with $\mathrm{OA},(2)$ no significant evidence for differential gene expression in the S-PrediXcan analyses, (3) limited evidence for this variant as an eQTL in brain tissues (Supplementary Table 13).

Drug repurposing analyses suggest druggability of all three genes: OPRM1, PPP6C, and FURIN. To

characterize the potential for new pharmacological treatments of OA through drug repurposing or compound development, we examined OPRM1, PPP6C, and FURIN across multiple drug repurposing databases (the

Drug Gene Interaction Database v.3.0 [DGldb], ${ }^{42}$ Connectivity Map [CMap], ${ }^{43}$ PHAROS

[https://pharos.nih.gov/44 ${ }^{44}$ OPRM1 is a known target of more than one-hundred drugs and compounds,

including illicit drugs, abused therapeutics (e.g., heroin and oxycodone), and OA treatments (e.g., methadone and buprenorphine)(Supplementary Table 15a-c). In contrast, PPP6C is not a target of any known drug or compound but has a $94 \%$ likelihood that its protein has ligand properties based on its chemistry. ${ }^{45} \mathrm{FURIN}$ is the target of one approved drug, pirfenidone, which is indicated for treatment of idiopathic pulmonary fibrosis. There are more than 80 compounds identified targeting FURIN, most developed as inhibitors targeting FURIN ¡5 function in infectious diseases: Supplementary Table 16a-c.

Testing previously reported GWAS variant associations supports three variants: rs1799971, rs62103177, and rs640561. Among the previously reported associations, the strongest association in the 
70 our gSEM was rs62103177 in the KCNG2 gene, which was nominally associated with OA in our EA cohort

$71 \quad(p=0.0024)$, though its initial report was among AA only and we were unable to test for replication in AAs owing

72 to a lack of available results that are independent of the initial study. ${ }^{46}$ The GENOA AA analyses are not

73 independent of the Yale-Penn cohorts in the original study. We extended our lookup of previously reported

74 variants to the standard logistic regression meta-analysis we ran with the subset of EA GWAS cohorts without

75 overlapping participants for previously reported EA specific findings. The CNIH3 variant, rs 10799590 , and the PGC-SUD variant, rs201123820, were not statistically significant in our standard meta-analysis ( $p=0.49$ and $\mathrm{p}=0.63$, respectively). Of the two $\mathrm{PH}$ reported variants, only rs 10014685 was present in independent cohorts, but it was not significant in either (deCODE $p=0.89$; UHS $p=0.36$ ). Examining a recently reported GWAS of

79 prescription opioid misuse $(\mathrm{POU}),{ }^{47}$ we see a moderate genetic correlation between $\mathrm{OA}$ and POU $\left(\mathrm{r}_{\mathrm{g}}=0.74\right.$, $30 p=2.24 \times 10^{-12}$ ) and extend their association of rs640561 to $\mathrm{OA}$ (rs640561-T, beta $=-0.061, p=0.009$ ). Finally, we 31 examined our gene-based GWAS results for evidence supporting previously reported genes and found no 32 support for GRM8 ( $p=0.591)$ or $C N I H 3(p=0.184)$, but nominal support for BEND4 ( $p=0.0023)$ association with 33 OA, which was reported as genome-wide significant in the PGC-SUD GWAS for the opioid use phenotype 34 (exposed vs. unexposed controls) ${ }^{26}$ and PTPRF for POU $(p=0.026) .^{47}$ 


\section{Discussion}

38 Opioid misuse, addiction, and overdoses remain at crisis levels in the United States. Identification of new

39 genetic drivers of OA phenotypes could lead to much needed new pharmacological treatments. In this study,

30 we demonstrated a high degree of genetic correlation between differing diagnostic and frequency-based case

31 definitions of $O A$ and across different types of controls (opioid exposed, unexposed, and population controls),

32 which allowed us to conduct the GENOA meta-analysis and apply gSEM successfully to GENOA and existing

33 summary statistics to conduct the largest GWAS among European ancestry cohort participants to date $(23,367$

34 cases and total effective sample size of 88,114 individuals) with the OA case definition. The GENOA GWAS

35 identified European ancestry specific genome-wide significant associations (rs28386916) but the variant was

36 not available in the MVP or PH cohorts and, consequently, was not tested for replication nor was the variant

37 present in the gSEM GWAS. In the gSEM GWAS we found the strongest statistical evidence to date linking

38 variants in intron 1 of the OPRM1 gene to OA, extending previous candidate gene studies focused on this

39 gene. ${ }^{37,48,49}$ Haplotype analysis of this locus indicated that the long studied and GWAS-identified variant

I0 rs1799971 (OPRM1-A118G) $)^{27}$ may not be the driving variant for this locus's association with OA. Gene-based

)1 analyses of these combined data also identified two novel genome-wide significantly associated genes for OA:

)2 PPP6C and FURIN. Examining the predicted differential expression of these genes in brain tissue and their

)3 colocalization with OA association signals suggest that the effect of the PPP6C locus on risk of OA is likely to

)4 be through effects on PPP6C expression, while the signal for OPRM1 is more complex; there is limited

J5 evidence that expression differences explain the association of FURIN with OA.

)6 The eight previously published GWAS of OA phenotypes have yielded inconsistent results. The first two

3 used small samples and numbers of variants: $\mathrm{N}=205$ European Americans $(E A s)^{21}$ and $\mathrm{N}=775 \mathrm{EAs}$ and $\mathrm{AAs}$. $^{22}$

18 No SNPs met genome-wide significance, but different variants in a glutamate receptor gene (GRM8) were

19 among the top candidate gene variants in both studies. ${ }^{22}$ The next two larger GWAS found genome-wide

I0 significant associations in two different genes: (1) a potassium channel gene (KCNG2) associated with number 
medRxiv preprint doi: https://doi.org/10.1101/2021.09.13.21263503; this version posted September 16, 2021. The copyright holder for this preprint (which was not certified by peer review) is the author/funder, who has granted medRxiv a license to display the preprint in perpetuity.

It is made available under a CC-BY-NC-ND 4.0 International license .

11 of opioid dependence symptoms among users (total $\mathrm{N}=5,432$ AAs and $p=3.6 \times 10^{-10}$ for $\mathrm{rs}^{6} 2103177$ ), ${ }^{46}$ and (2)

SNPs in a regulator gene of the glutamate system $(\mathrm{CNIH} 3)$ associated with opioid dependence (total $\mathrm{N}=2,637$ of European ancestry and smallest $p=4.3 \times 10^{-9}$ for $r$ 10799590). ${ }^{24}$ The most recent and largest OA GWAS to date are from the PGC-SUD, ${ }^{26} \mathrm{MVP},{ }^{27}$ and $\mathrm{PH},{ }^{28}$ which were incorporated in our gSEM GWAS. The PGCSUD examination of opioid use disorder (OUD; $N=4,503$ OUD cases, 4,173 opioid-exposed controls) found no genome-wide significant associations; the analysis of OUD vs unexposed controls among $A A s(N=1,231$ cases, 6,111 controls) found one genome-wide significant association (rs201123820 $\left[p=2.9 \times 10^{-8}\right]$ ) but no clear connection to addiction. The MVP tested for variant associations with OUD cases and opioid-exposed controls, finding one genome-wide significant association $\left(p=1.51 \times 10^{-8}\right)$ for rs 1799971 in OPRM1. Genomewide significance was achieved by combining the MVP EA cohort with Yale-Penn and SAGE EA cohorts for a combined sample of 10,544 cases and 72,163 controls. PH tested variant associations among EAs with OUD cases defined by ICD9 and ICD10 codes $(\mathrm{N}=1,039)$ compared to both general controls without substance use disorder diagnoses $(\mathrm{N}=20,271)$ and a subset that also had a medical record of having been prescribed an opioid $(\mathrm{N}=10,744)$. Analyses using both control groups identified a genome-wide significant locus on chromosome 4 ( $\mathrm{rs} 10014685\left[p=2.40 \times 10^{-8}\right.$ using all controls and $p=1.75 \times 10^{-9}$ using exposed controls]), while the exposed control analysis found an additional locus on chromosome 16 ( $r$ 12931235 $\left.\left[p=7.18 \times 10^{-10}\right]\right)$. OUD associations for these loci, both intergenic and of unclear functional relevance to OUD. Testing these previously reported variants in the gSEM and standard meta-analysis GWAS results found support for three variants, rs1799971, rs62103177, rs640561. Although the original association between rs62103177 and opioid dependence was found among AAs only, our gSEM results extend that association to EAs. We were unable to test for replication in AAs due to a lack of independent AA GWAS results. rs62103177 is an intronic variant in the potassium voltage-gated channel modifier subfamily G member 2 (KCNG2) gene, which has been suggested to have a role in substance use disorders. ${ }^{23,50}$ In GTEx, this variant is also an expression 
medRxiv preprint doi: https://doi.org/10.1101/2021.09.13.21263503; this version posted September 16, 2021. The copyright holder for this preprint (which was not certified by peer review) is the author/funder, who has granted medRxiv a license to display the preprint in perpetuity.

It is made available under a CC-BY-NC-ND 4.0 International license .

$35\left(p<6.1 \times 10^{-6}\right.$ across 12 GTEx brain tissues). Additional evaluation of this variant and its function in brain are 36 supported by these results.

The top finding of this gSEM GWAS for OA was centered in intron 1 of the OPRM1 gene (lead SNP rs9478500-C, beta $\left.=0.136, p=2.56 \times 10^{-9}\right)$. Prior candidate gene studies of this region have found nominal associations of variants in intron 1, including some of those that are genome-wide significant here (e.g., rs1381376, rs3778151, \& rs3778150). ${ }^{37,48,49}$ As the mu-opioid receptor gene, OPRM1 has long been a target of OA research and drug development. The functional coding variant rs1799971 (A118G), encoding the amino acid change Asn40Asp, has been studied at length with equivocal results. ${ }^{37,51,52}$ In the current GWAS era, only the MVP GWAS of OUD found rs1799971 to be genome-wide significant $\left(p=1.51 \times 10^{-8}\right) \cdot{ }^{27}$ Adding cohorts to the MVP summary statistics in the current study reduced the variant's association with OA to $p=1.94 \times 10^{-6}$, which may be due to variation in haplotype prevalence between studies (discussed below), increase in phenotypic heterogeneity (despite high overall genetic correlations among OA phenotypes), or stochastic variation. haplotypes with OA. Three haplotypes were formed by rs1799971 and the genome-wide significant variants: (A) a haplotype with major alleles at all variants; (B) a haplotype with the minor rs1799971-G allele and major alleles at all other variants; and (C) a haplotype with the major rs1799971-A allele and minor alleles at all other variants. In this analysis, the $O A$ association was strongest with haplotype $C\left(p=2.43 \times 10^{-9}\right)$, which was associated with increased risk compared to both haplotype $A$ and haplotype $B$. Haplotype $B$, which carried the rs1799971-G allele, was strongly not significant ( $p=0.52)$. Evaluation of haplotype associations with OA in this study were limited to a subset of the cohorts for which we had raw genotype data. In this subset, the variant level association for $r 1799971$ was also not significant $(p=0.135)$, which limits the strength of our conclusions. However, our earlier haplotype analyses of OPRM1 intron 1 variants and rs1799971 came to similar conclusions, albeit in more limited datasets. ${ }^{37,38}$ This relationship between the underlying EA haplotype 
medRxiv preprint doi: https://doi.org/10.1101/2021.09.13.21263503; this version posted September 16, 2021. The copyright holder for this preprint (which was not certified by peer review) is the author/funder, who has granted medRxiv a license to display the preprint in perpetuity.

It is made available under a CC-BY-NC-ND 4.0 International license .

structure and risk for OA may explain the equivocal findings at the individual rs1799971 variant level, but it may be that other unidentified variants could be the true causal variants driving these haplotype associations.

The role of genetically driven OPRM1 expression also appeared complex in this study. In our SPrediXcan analysis, we observed statistically significant, predicted differential expression of OPRM1 for OA in cerebellum, the brain tissue with the highest level of OPRM1 expression in GTEx. Moreover, one of the two cis-eQTL variants in the version 8 GTEx model for OPRM1 expression (rs478498) is in high LD with our top association variant $\left(r s 9478500 ; r^{2}=0.56, D^{\prime}=0.98\right)$, suggesting that the intron 1 locus may have its effect on $O A$ through OPRM1 expression. However, the colocalization analysis was more equivocal. The hypotheses with the greatest posterior probabilities were that both OPRM1 expression and OA risk are associated with this locus, but with different causal variants $(\mathrm{H} 3$, posterior probability $=0.46)$ and with a single causal variant $(\mathrm{H} 4$, posterior probability=0.38). Given the generally low level of OPRM1 expression across bulk brain tissues, larger sample sizes and single nuclei experiments will be needed to further distinguish which of these hypotheses is most likely. Ultimately, model organism or organoid experiments are likely to be necessary to fully test gene expression as a potential mechanism for the association of this locus with OA.

Beyond OPRM1, we also observed a genome-wide significant association with OA for the intergenic variant rs13333582. Variants in high LD had much weaker associations $\left(p=2.25 \times 10^{-3}\right)$, which may indicate that the rs13333582 association with OA was a false positive. However, rs13333582 is an eQTL for RANBP10 in multiple brain tissues (Supplementary Table 17). RANBP10 has been associated with regulation of dopamine $D_{1}$ and mu-opioid receptors ${ }^{53}$ and was recently linked with the variant rs8052287 and substance use disordergene interactions that included opioids. ${ }^{54}$ LD between rs13333582 and rs8052287 is moderate in European ancestry $\left(r^{2}=0.60, D^{\prime}=0.81\right)$. However, the association between $r 8052287$ and OA in this gSEM GWAS was only nominally significant (beta $=-0.083, p=0.0239)$.

Increasing statistical power through a gene-based GWAS of the gSEM summary statistics identified two new genome-wide significant genes for OA: PPP6C and FURIN. PPP6C (Protein Phosphatase 6 Catalytic 
medRxiv preprint doi: https://doi.org/10.1101/2021.09.13.21263503; this version posted September 16, 2021. The copyright holder for this

preprint (which was not certified by peer review) is the author/funder, who has granted medRxiv a license to display the preprint in perpetuity.

It is made available under a CC-BY-NC-ND 4.0 International license .

32 subunit gene) is a component of a signaling pathway regulating cell cycle progression known to be involved 33 with the immune system and cancer(https://www.uniprot.org/uniprot/O00743\#function) However, the gene is 34 also strongly expressed across adult human brain tissues (Supplementary Figure 17c) and is linked to abnormal locomotor behavior in mice (http://www.informatics.jax.org/diseasePortal/genoCluster/view/20628). ${ }^{55}$

36 Predicted biological processes for PPP6C include G-protein coupled purinergic nucleotide receptor signaling pathway (GO:0035589) (https://maayanlab.cloud/archs4/gene/PPP6C), which affects regulation of neurons, microglia and astrocytes ${ }^{56}$. Predicted genetically driven differential expression of PPP6C by OA was significant across a number of brain regions, and colocalization analysis of PPP6C cis-eQTLs and the OA-variant association signal at this locus also showed high probability of being driven by a shared single variant. Because the PPP6C-centered association locus extends into the nearby genes SCAI and RABEPK, and significant predicted genetically driven differential expression of SCAl was also observed, we cannot exclude the possibility that these other genes play a role in, or are responsible for, the PPP6C-OA association. However, the degree of gene expression/variant association colocalization for PPP6C across brain tissues suggest it as the leading candidate for follow-up studies.

The genome-wide significant gene-based association of OA with FURIN was driven by a single variant, rs17514846. However, this signal was supported by analysis of additional FURIN variants in a subset of cohorts where more FURIN variants were available, including a genome-wide significant association with $O A$ at the variant level for rs11372849. FURIN (Furin, Paired Basic Amino Acid Cleaving Enzyme gene) is a member of the convertase family and encodes a type 1 membrane bound protease that is expressed in neuroendocrine and brain tissues, among others (https://www.ncbi.nlm.nih.gov/gene/5045). Although FURIN shows higher expression across brain tissues than OPRM1, the S-PrediXcan analysis did not show significant predicted genetically driven expression differences associated with OA for this gene, and the colocalization analysis highest posterior probabilities favored no association of either eQTLs or the OA-variant association 
signal at this locus. However, this may reflect the single variant association with OA in the gSEM GWAS and an effect on OA through mechanisms other than gene expression.

LDSC analyses demonstrated moderate to strong genetic correlations between OA and a variety of substance use, psychiatric, and cognitive phenotypes in expected directions (e.g., positive correlation with cannabis use disorder, inverse correlation with age of smoking initiation). Focusing from the general genomic signal to the specific OA-associated genes, we observed important differences in OPRM1, PPP6C, and FURIN associations with brain- and SUD-related phenotypes. Although OPRM1 has been broadly studied, from a GWAS perspective variants in this gene are specifically associated with OUD in the MVP GWAS ${ }^{57}$ and in a GWAS of methadone dose. ${ }^{58}$ No GWAS of other brain- or SUD-related phenotypes have reported an association with OPRM1, as indexed by Open Targets (Supplementary Figure 18; Supplementary Table 14a). ${ }^{59,60}$ The variant associated with methadone dose, rs73568641, was not associated with OA in this gSEM GWAS $(p=0.328)$. In contrast with OPRM1, variants in PPP6C have been associated with numerous brain- and SUD-related phenotypes, notably opioid medication use, alcohol consumption, numerous smoking phenotypes, and depression among others (Supplementary Figure 19; Supplementary Table 14b). Indeed, the specific PPP6C variants associated with OA in this gSEM GWAS, albeit at $\mathrm{p}$-values in the $10^{-7}$ range, have been associated with neuroticism, depressive symptoms and a number of smoking phenotypes at genome-wide significance (Supplementary Table 14b). Variants in FURIN have been associated with other brain- and SUDrelated phenotypes, most predominantly schizophrenia, but also risk taking, number of sexual partners, and insomnia (Supplementary Figure 20; Supplementary Table 14c). The variant driving the genome-wide significant gene-based result here (rs17514846) and the genome-wide significant variant in our subset metaanalysis for OA (rs11372849) are associated with each of these Open Target-identified phenotypes at genome-wide significance (Supplementary Table 14c).

Similar variability was seen across OPRM1, PPP6C, and FURIN in drug repurposing analyses. While OPRM1 is the known target of more than one-hundred drugs and compounds, FURIN is the target of one 
approved drug (pirfenidone), and PPP6C is not a target of any known drug or compound across the databases evaluated: DGIdb ${ }^{42}, \mathrm{CMap}^{43}$ and PHAROS. ${ }^{44}$ However, FURIN is the target of more than 80 compounds and the PPP6C protein has a 94\% likelihood of being ligandable. Should these novel gene associations be validated in subsequent studies they appear to be potentially important drug development targets.

Among this study's limitations, the most notable is the focus on cohorts of European ancestry. This focus was required to maximize sample size and statistical power by combining summary statistics across GENOA, wide significance for $r s 1799971$ ( $n=23,367$ vs $n=10,544$ ) by leveraging gSEM's ability to model multiple correlated phenotypes and account for sample overlap. These gSEM analyses will be extended to African Americans when the needed ancestry-specific LDSC reference panel becomes available. An additional potential limitation is the variability in OA case definitions (e.g., diagnostic and frequency of use) and types of controls (e.g., exposed, unexposed, and population-based) used to define OA phenotypes across the cohorts within the GENOA and across the other contributing GWAS. However, the genetic correlations across phenotypes were uniformly high $\left(r_{g}>0.9\right)$ and resulted in a well-fitting single latent factor gSEM model. An important caveat to the high correlations observed across cohorts with exposed, unexposed, and population controls is that the exposure to opioids was often based on prescribed medication (MVP and PH), which differs in risk of OA from exposure to illicit heroin use. Fine-grained comparison of large samples with different types of exposure to opioids will be needed to resolve this question. Because we have incorporated GENOA and previously published GWAS of OA for our discovery analyses, we do not have independent replication cohorts available in which to test the identified associations. However, OA associations with the intron 1 locus have been previously reported, ${ }^{29,37,48,49}$ the chromosome 16 (rs13333582) is an eQTL for a gene previously reported as associated with $O A,{ }^{54}$ and variants in both PPP6C and FURIN have previously been associated with 
and 13). Thus, independent replication remains to be demonstrated, but the available evidence supports the

j4 identified variants and genes as associated with OA.

j5 In this study, we leveraged gSEM across new and existing OA GWAS that employed various OA j6 phenotypes to conduct the largest EA-focused GWAS to date. Our results show the strongest statistical j7 evidence to date for an association between variants in intron 1 of OPRM1 with OA. Haplotype analysis of the genome-wide significant variants and previously associated rs1799971 (A118G) suggest that it is the intron 1 variants rather than rs1799971 that is responsible for this association signal, although other unidentified variants outside the tested haplotypes could explain the observed results. Gene-based analyses identified two genome-wide significant associations: PPP6C and FURIN. These genes are novel for OA, however, variants within them have been associated at genome-wide significance with related phenotypes, such as cigarette smoking, alcohol consumption, general risk taking, and schizophrenia. With strong SNP-based heritability for these OA phenotypes, but only these few genome-wide significant findings, it is clear that increased sample 


\section{Methods}

72 Cohorts and Opioid Addiction Phenotype. Descriptive statistics for the GENOA studies contributing 73 previously unpublished GWAS of opioid addiction $(\mathrm{OA})$ to this investigation are provided in Supplementary

74 Table 1, and full descriptions of the studies are provided in the Supplementary Methods. In total, this analysis 75 provides new OA GWAS results for 304,831 individuals, including 7,281 cases and 297,550 controls, with an 76 effective sample size of 88,114 (4 / ((1 / \# Cases $)+(1 /$ \# Controls $)))^{61,62}$ and Statistical Manual (DSM) of Mental Disorders criteria. Some studies included only opioid-exposed individuals in their control groups, while others included both exposed and unexposed individuals.

Genotype Quality Control and Imputation. Sites in the GENOA consortium conducted standard genotype quality control using filters appropriate for their samples. SNPs were filtered based on call rate and deviation from Hardy-Weinberg equilibrium. Samples were filtered based on call rate, excessive homozygosity, relatedness, and sex discrepancies. Classification of European ancestry individuals was based on comparison to reference populations using STRUCTURE ${ }^{63}$. Specific filters used for each sample are provided in Supplementary Table 18.

For most samples, genotype imputation was performed with the Michigan Imputation Server ${ }^{64}$ using the 1000 Genomes Phase 3 v5 reference panel. For COGA, genotypes were phased with SHAPEIT2 ${ }^{65}$ and imputed with Minimac $3^{64}$ using the 1000 Genomes Phase 3 v5 reference panel. For deCODE, genotype imputation was conducted by long-range phasing and haplotype imputation of chip-genotyped individuals with methods described previously ${ }^{66}$. 
33 Association Testing. Imputed genotypes for GENOA studies were tested for association with opioid addiction )4 case-control status using rvtests ${ }^{67}$, adjusting for sex, age, genotype principal components and in some cases 35 recruitment site and other study-specific covariates. deCODE data were analyzed using logistic regression 36 treating disease status as the response and imputed genotype counts as covariates. Other available 37 individual characteristics that correlate with disease status were also included in the model as nuisance 38 variables (sex, age, county of origin(ref1), blood sample availability, and an indicator function for the overlap of 39 the lifetime of the individual with the time span of phenotype collection) using previously described methods. ${ }^{68}$ j0 To account for inflation due to population stratification and relatedness, test statistics were divided by an )1 inflation factor (1.10) estimated from linkage disequilibrium score regression (LDSR). ${ }^{69}$ Inverse variance)2 weighted meta-analysis of chromosome 15 variants with $M A F<0.01$ and $R s q<0.8$ in the region containing )3 FURIN was performed using METAL ${ }^{70}$ including only studies with no overlapping samples (GENOA + MVP )4 without SAGE and Yale-Penn + Partners; Cases $N=16,849$, Controls $N=379,493$, Total $N=396,342$, )5 Effective Total $\mathrm{N}=52,508)$. 
)7 Cohort Descriptions for GenomicSEM. The gSEM analysis includes results on EA from the GENOA meta8 analysis, Million Veteran Program (MVP), Psychiatric Genetics Consortium Substance Use Disorders Group )9 (PGC-SUD), and the Partners Health cohorts. The MVP results are based on a meta-analysis including MVP I0 parts 1 and 2 (total of 8,529 OUD cases and 71,200 opioid-exposed controls), along with Yale-Penn and Study

I1 of Addition: Genetics and Environment (SAGE) cohorts (total of 10,544 OUD cases and 72,163 opioid-exposed 12 controls). ${ }^{27}$ The PGC-SUD results include 4,503 opioid dependence cases and 4,173 unexposed controls. ${ }^{26}$ I3 Unexposed controls are used for the PGC-SUD because the exposed controls results have negative heritability I4 estimates. The partners health cohort includes 1,039 OUD cases and 10,743 exposed controls. ${ }^{28}$ Note that the I5 GENOA GWAS, Yale-Penn, and SAGE parts of the MVP, and the PGC-SUD results include overlapping I6 samples. However, accounting for this sample overlap is a feature of the gSEM approach applied in this study. I7 A total of 2,434,903 variants were present in all cohorts and tested for association with the OA latent variable in I8 the gSEM analysis using a total sample size of 403,915 (23,367 cases and 384,619 controls; effective sample 19 size of 88,115$)$. 
21 Genomic Structural Equation Modeling. The GenomicSEM package ${ }^{30}$ within R was used for genomic

?2 structural equation modeling (gSEM). The gSEM implemented multivariable LDSC function within this package

?3 was used to calculate single-nucleotide polymorphism heritability on the observed and liability scale

?4 (prevalence of 10\%), genetic covariance matrices, and genetic correlation. The LD scores from 1000 Genomes

?5 Project phase 3 European ${ }^{69}$ were used as the reference population in this calculation. The sampling genetic

?6 covariance matrix is expanded to incorporate SNP effects by including the covariances between SNPs and

?7 each cohort. This expanded sampling genetic covariance includes the multivariate LDSC estimated genetic

?8 variances and covariances, along with the sampling covariance matrix of the SNP effects on the cohorts, which

?9 are estimated using cross-trait LDSC with the sampling correlation weighted by the sample overlap. With the

30 gSEM implemented LDSC, the overlap of samples between GENOA, MVP meta-analysis, and PGC-SUD is 31 not a concern.

A single latent factor gSEM was used with the residual variance of the latent factor set to 1 to normalize

33 the loading estimates. The loadings were calculated using diagonally weighted least squares and residual

34 variances were bound to above 0.01 to avoid negative residual variance estimates. 
36 Haplotype Analyses. To conduct haplotype analyses raw genotype data is needed. Chromosome 6

37 genotypes were available from UHS, VIDUS, ODB, Yale-Penn, CATS and Kreek (Supplementary Table 1).

38 These cohorts' data were phased with Eagle v2.4 via the Michigan Imputation Server ${ }^{64}$. Haplotypes for

39 samples from each study were constructed by extracting OPRM1 variants that were genome-wide significant in

10 the gSEM analysis and concatenating ordered by genomic position. Supplementary Table 19 provides counts

$\$ 1$ for the various haplotypes observed across the studies. The 3 most common haplotypes, which accounted for $98 \%$ of observed haplotypes, were tested for association with OA in R adjusting for sex and genotype principal components. Only individuals carrying exclusively these haplotypes were included in the analysis. Two models were run, one in which the haplotype containing all major alleles served as the reference haplotype and one in which the haplotype containing the minor rs1799971-G allele served as the reference. This approach provided three effective comparisons: (a) rs1799971-G haplotype versus the major allele haplotype; (b) minor allele + rs1799971-A haplotype versus the major allele haplotype; (c) minor allele + rs1799971-A haplotype versus rs1799971-G haplotype. Individual cohort results were combined in an inverse variance-weighted metaanalysis using METAL $(\mathrm{N}=21,037)$.

Gene-Based Analyses. Gene-based associations with OA were calculated from the gSEM summary statistics with MAGMA v1.08 ${ }^{39}$ with a $10 \mathrm{~kb}$ gene window via the Functional Mapping and Annotation (FUMA) of GWAS web tool v1.3.6a ${ }^{71}$. The gSEM summary statistics were mapped to 15,977 protein coding genes, resulting in a 
medRxiv preprint doi: https://doi.org/10.1101/2021.09.13.21263503; this version posted September 16, 2021. The copyright holder for this

preprint (which was not certified by peer review) is the author/funder, who has granted medRxiv a license to display the preprint in perpetuity.

It is made available under a CC-BY-NC-ND 4.0 International license .

j6 Cross-trait genetic correlations with OA. Summary statistics from the gSEM were used as input into LD

77 score regression (LDSC) with reference to the 1000 Genomes EUR panel to estimate genetic correlations

;8 between OA and 38 other complex phenotypes. These phenotypes were categorized into the following groups:

¡9 drug and alcohol use, cigarette smoking, psychiatric, personality, neurological, cognitive/education, and brain

i0 volume. The full list of phenotypes and GWAS datasets, as obtained from LD Hub or shared by the original

i1 investigators, are provided in the Supplementary Table 20.

i2

PrediXcan. To investigate the transcriptome-wide associations between predicted gene expression and OA,

i4 we employed the MetaXcan v0.6.6 ${ }^{40}$ method. Briefly, MetaXcan uses association summary statistics to predict associations between gene expression and a phenotype of interest association. Gene expression models were predicted from tissue-specific eQTL datasets. To increase the performance of our prediction models, we used the MASHR-M ${ }^{72}$ models built on fine-mapped variables from DAP-G. ${ }^{73}$ The specific models we used were precomputed MetaXcan models available through PredictDB (http://predictdb.org/) for 12 brain regions (Supplementary Table 21) that were generated using the GTEx ${ }^{74}$ version 8 datasets.

Summary level statistics from the Genomic SEM analysis were used as input to MetaXcan. Prior to input, summary statistics were harmonized according to the best practices guide outlined on the MetaXcan wiki. As part of this process, the gwas_parsing.py utility (https://github.com/hakyimlab/summary-gwasimputation) was used to lift summary statistics over to the human genome build version 38 and provide harmonized variant identifiers compatible with those used by GTEx v8. To increase the number of overlapping markers between our summary statistics and the fine-mapped pre-built MASHR models, we imputed missing summary associations as suggested by the best practices workflow. Imputation was performed separately for each chromosome using the gwas_summary_imputation.py utility (https://github.com/hakyimlab/summary78 gwas-imputation) and the pre-computed parquet genotype, genotype metadata files, and European LD block 
79 files available through the MetaXcan zenodo repository ${ }^{75}$. Imputed summary statistics were finally re-

30 combined using the gwas_summary_imputation_postprocess.py utility.

31 The resulting imputed, harmonized association summary statistics were then used as input to

MetaXcan. The number of genes tested for each tissue is found in Supplementary Table 21. FDR correction

was applied to account for the number of genes tested across all tissues (156215 total tests). A gene's

predicted expression was considered significantly associated with OA if its FDR-adjusted p-value fell below a threshold of 0.05 .

Colocalization. Co-localization analysis was performed using the coloc package in $\mathrm{R} .{ }^{76}$ Cis-eQTL data for

38 individuals of European ancestry from the GTEx v8 eQTL Tissue-Specific All SNP Gene Associations dataset

39 (dbGaP Accession phs000424.v8.p2) were input as a quantitative trait into coloc (sample sizes for each tissue

30 type indicated in Supplementary Table 22). Summary statistics from the gSEM analysis were input as a

31 quantitative trait, with a sample size of 403,915 . Summary statistics from the standard meta-analysis of $O A$

)2 were input as a case-control trait with 16,849 cases and 379,493 controls. All SNP positions were lifted over to

33 build 38. The cis-eQTL data was partitioned into blocks based on the gene in the SNP-gene pair. For each

34 gene block, only SNPs in the gSEM or meta-analysis summary statistics overlapping with the cis-eQTL data

35 were input into the coloc function for (approximate) Bayes Factor colocalization analysis.

\section{Data availability}

38 The GWAS summary statistics generated and/or analyzed during the current study will be made available via $39 \mathrm{dbGAP}$; the dbGaP accession assigned to the UHS is phs000454.v1.p1. The website is

J0 https://www.ncbi.nlm.nih.gov/projects/gap/cgi-bin/study.cgi?study_id=phs000454.v1.p1 


\section{Acknowledgements.}

)3 The late Dr. Mary Jeanne Kreek from the Laboratory of the Biology of Addictive Diseases at the Rockefeller

)4 University, New York, NY, was a key contributor to the research presented in this manuscript.

5

)6 We thank deCODE genetics for contributing summary statistics from their analysis of opioid addiction in the deCODE cohort. We particularly thank Kari Stefansson, Thorgeir Thorgeirsson, Valgerdur Runarsdottir,

)8 Thorarinn Tyrfingsson, Gudmundur Einarsson, and Daniel F. Gudbjartsson for their work to generate and 9 share these results.

11 Funding.

The National Institute on Drug Abuse: R01DA044014, R01DA038632, R33DA027486 (EOJ, NG, DBH); K01DA036751 (RCC), U10DA13043 (WHB), R01DA04401 (RCC, WHB)

The Dr. Miriam and Sheldon G. Adelson Medical Research Foundation (OL, MR, MJK), The Clinical and

Translational Science Award UL1RR024143 from the National Center for Advancing Translational Sciences of 17 the NIH (MJK). non-formulary grant Pharmacogenetics of Opioid Use Disorder (RCC, WHB).

U01AA008401 (LW, DL, KB, TF, AA, BP, HE); Pennsylvania State Department of Health Tobacco Settlement

The Genotype-Tissue Expression (GTEx) Project was supported by the Common Fund of the Office of the Director of the National Institutes of Health, and by NCI, NHGRI, NHLBI, NIDA, NIMH, and NINDS. The data used for the analyses described in this manuscript were obtained from: GTEx Analysis v8 of the GTEx Portal on 05/18/21 and/or dbGaP accession number phs000424.v8.p2 on 02/17/2021. 
medRxiv preprint doi: https://doi.org/10.1101/2021.09.13.21263503; this version posted September 16, 2021. The copyright holder for this preprint (which was not certified by peer review) is the author/funder, who has granted medRxiv a license to display the preprint in perpetuity.

It is made available under a CC-BY-NC-ND 4.0 International license . 


\section{$? 7 \quad$ Tables}

:8 Table 1. Fourteen gene-brain region combinations exhibiting predicted genetically driven differential gene 29 expression in human brain regions associated with OA (across tissue FDR $<0.05$ ) in analysis of gSEM GWAS 30 summary statistics with S-PrediXcan analysis using GTEx version 8 eQTL gene models.

\begin{tabular}{|l|l|r|}
\hline Gene & Tissue & Across Tissue FDR \\
\hline OPRM1 & Cerebellum & 0.009 \\
\hline SCAI & Cerebellum & 0.009 \\
\hline SCAI & Frontal cortex & 0.009 \\
\hline SCAI & Hippocampus & 0.009 \\
\hline PPP6C & Hippocampus & 0.009 \\
\hline PPP6C & Anterior cingulate cortex & 0.01 \\
\hline PPP6C & Cerebellar hemisphere & 0.01 \\
\hline PPP6C & Putamen basal ganglia & 0.01 \\
\hline PPP6C & Caudate basal ganglia & 0.01 \\
\hline SCAI & Cortex & 0.01 \\
\hline PPP6C & Cortex & 0.01 \\
\hline PPP6C & Frontal cortex & 0.01 \\
\hline PPP6C & Hypothalamus & 0.01 \\
\hline & Nucleus accumbens basal & 0.01 \\
\hline PPP6C & ganglia &
\end{tabular}


medRxiv preprint doi: https://doi.org/10.1101/2021.09.13.21263503; this version posted September 16, 2021. The copyright holder for this preprint (which was not certified by peer review) is the author/funder, who has granted medRxiv a license to display the preprint in perpetuity.

It is made available under a CC-BY-NC-ND 4.0 International license .

\section{Figures}


medRxiv preprint doi: https://doi.org/10.1101/2021.09.13.21263503; this version posted September 16, 2021. The copyright holder for this preprint (which was not certified by peer review) is the author/funder, who has granted medRxiv a license to display the preprint in perpetuity.

(a)

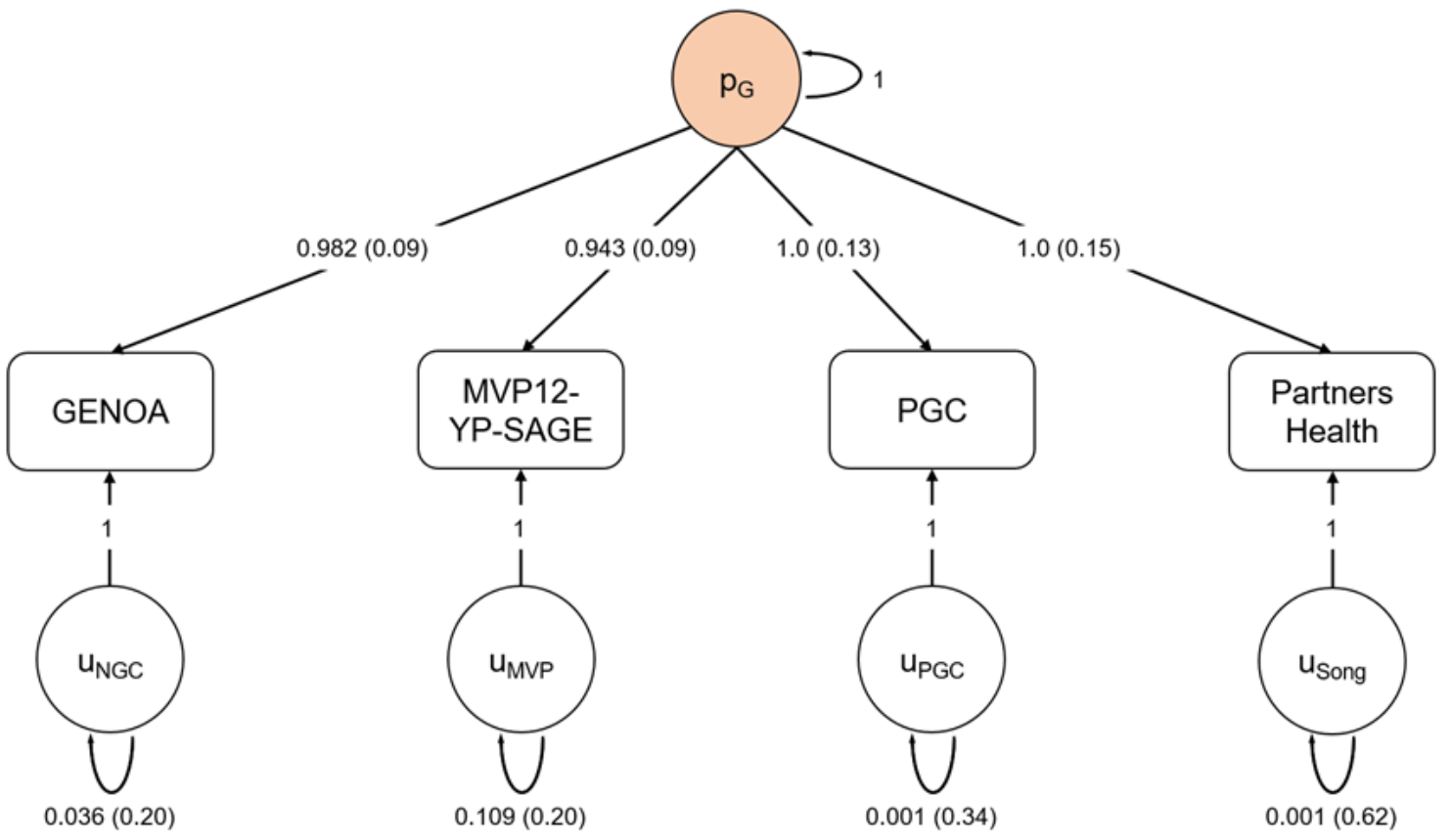

\begin{tabular}{|l|l|l|l|l|l|}
\hline \multicolumn{6}{|l|}{ Model Fit } \\
\hline Chi-square & Df & P-value & AIC & CFI & SRMR \\
\hline 0.857 & 2 & 0.958 & 16.086 & 1 & 0.020 \\
\hline
\end{tabular}

(b)

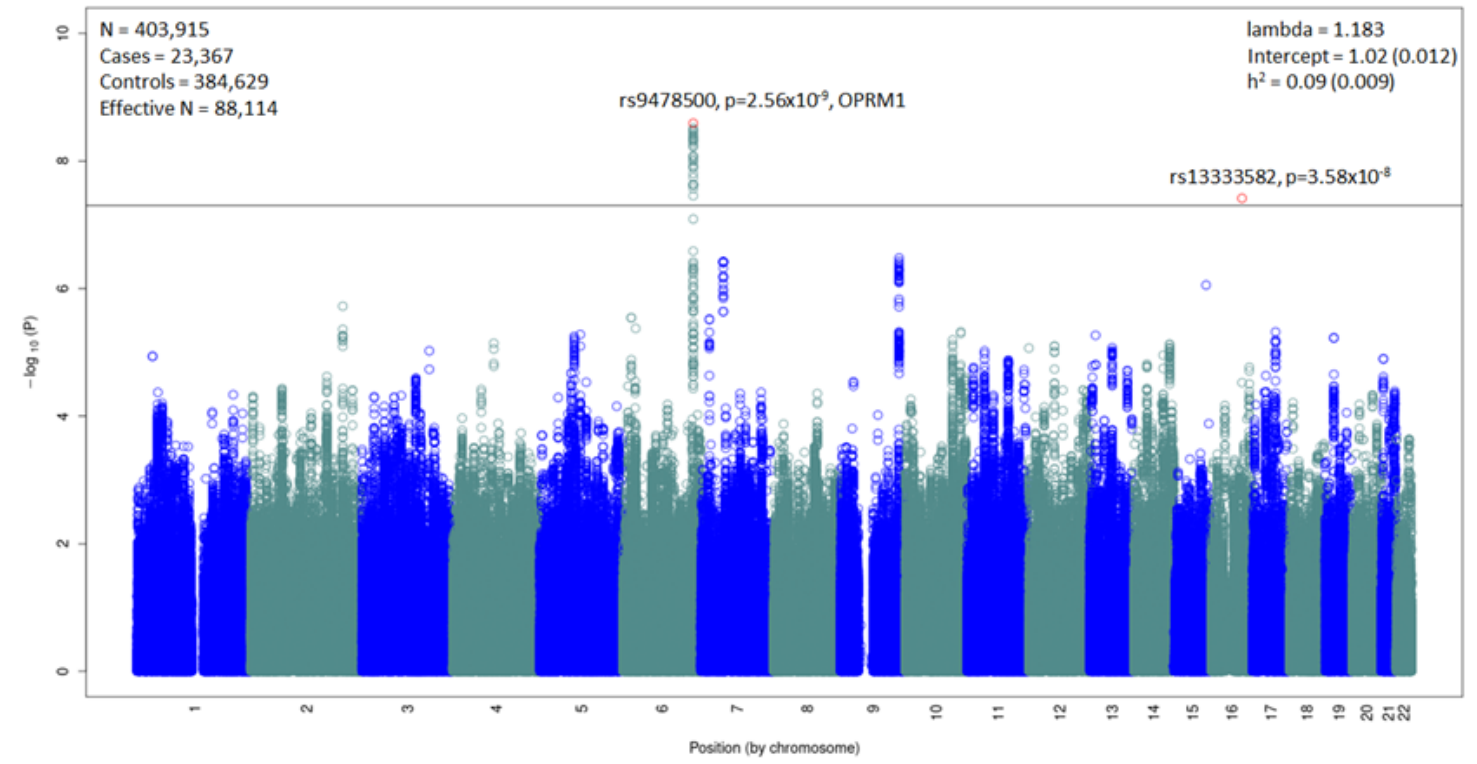


medRxiv preprint doi: https://doi.org/10.1101/2021.09.13.21263503; this version posted September 16, 2021. The copyright holder for this preprint (which was not certified by peer review) is the author/funder, who has granted medRxiv a license to display the preprint in perpetuity. It is made available under a CC-BY-NC-ND 4.0 International license .

35 Figure 1. Genomic SEM model and Manhattan plot. (a) A common factor $\left(p_{g}\right) \mathrm{gSEM}$ model (using

36 GenomicSEM) is fit with summary statistics from GENOA, MVP12-YP-SAGE, PGC, and Partners Health

37 cohorts. Standardized estimates and standard errors are shown for each free parameter. Model fit is shown by

38 a non-significant chi-square test, high Akaike information criterion (AIC, higher is better) and comparative fit

39 index $(\mathrm{CFI})$ equal to exactly 1.0 , and low standardized root mean squared root $(\mathrm{SRMR})$ values (ideal $<0.05)$

10 (b) Manhattan plot for gSEM results with summary statistics from GWAS from each cohort. Bonferroni

H1 correction was used to correct for multiple comparisons; associations with $\mathrm{P}<2 \times 10^{-8}$ (indicated by horizontal

t2 black bar) were considered to be genome-wide significant (top SNP highlighted in red). 
medRxiv preprint doi: https://doi.org/10.1101/2021.09.13.21263503; this version posted September 16, 2021. The copyright holder for this preprint (which was not certified by peer review) is the author/funder, who has granted medRxiv a license to display the preprint in perpetuity.

It is made available under a CC-BY-NC-ND 4.0 International license .

(a)

\begin{tabular}{|c|c|c|c|c|}
\hline A & B & $\mathrm{C}$ & Variant & Chr. 6 Position \\
\hline $\mathrm{A}$ & $\mathrm{G}$ & $\mathrm{A}$ & rs1799971 & 154360797 \\
\hline$A$ & $\mathrm{~A}$ & $\mathrm{G}$ & rs9322445 & 154362254 \\
\hline $\mathrm{A}$ & $\mathrm{A}$ & $\mathrm{C}$ & rs3778145 & 154367080 \\
\hline $\mathrm{T}$ & $\mathrm{T}$ & $\mathrm{C}$ & rs3778146 & 154377925 \\
\hline $\mathrm{T}$ & $\mathrm{T}$ & $\mathrm{C}$ & rs9478500 & 154378223 \\
\hline $\mathrm{G}$ & $\mathrm{G}$ & $\mathrm{A}$ & rs3778147 & 154378739 \\
\hline $\mathrm{G}$ & $\mathrm{G}$ & $\mathrm{A}$ & rs3823010 & 154379152 \\
\hline $\mathrm{C}$ & $\mathrm{C}$ & $\mathrm{T}$ & rs9285542 & 154379934 \\
\hline $\mathrm{G}$ & $\mathrm{G}$ & $\mathrm{T}$ & rs3778148 & 154381012 \\
\hline $\mathrm{C}$ & $\mathrm{C}$ & $\mathrm{G}$ & rs3778149 & 154382139 \\
\hline $\mathrm{C}$ & $\mathrm{C}$ & $\mathrm{T}$ & rs7773995 & 154382367 \\
\hline $\mathrm{G}$ & $\mathrm{G}$ & $\mathrm{A}$ & rs7772959 & 154382473 \\
\hline $\mathrm{A}$ & $\mathrm{A}$ & $\mathrm{G}$ & rs7759522 & 154382639 \\
\hline $\mathrm{T}$ & $\mathrm{T}$ & $\mathrm{C}$ & rs9479754 & 154383058 \\
\hline $\mathrm{T}$ & $\mathrm{T}$ & $\mathrm{C}$ & rs3778150 & 154383658 \\
\hline $\mathrm{T}$ & $\mathrm{T}$ & $\mathrm{C}$ & rs9478501 & 154384531 \\
\hline $\mathrm{A}$ & $\mathrm{A}$ & $\mathrm{C}$ & rs12333298 & 154386364 \\
\hline $\mathrm{T}$ & $\mathrm{T}$ & $\mathrm{C}$ & rs73014269 & 154387204 \\
\hline $\mathrm{G}$ & $\mathrm{G}$ & $A$ & rs73014273 & 154387211 \\
\hline $\mathrm{T}$ & $\mathrm{T}$ & $\mathrm{G}$ & rs6927269 & 154388306 \\
\hline $\mathrm{A}$ & $\mathrm{A}$ & $\mathrm{C}$ & rs73014276 & 154389347 \\
\hline $\mathrm{A}$ & $\mathrm{A}$ & $\mathrm{G}$ & rs7453922 & 154389783 \\
\hline $\mathrm{G}$ & $\mathrm{G}$ & $\mathrm{A}$ & rs1461773 & 154391369 \\
\hline $\mathrm{T}$ & $\mathrm{T}$ & $\mathrm{C}$ & rs9478503 & 154392675 \\
\hline $\mathrm{C}$ & $\mathrm{C}$ & $\mathrm{T}$ & rs1381376 & 154393258 \\
\hline $\mathrm{T}$ & $\mathrm{T}$ & $\mathrm{C}$ & rs3778151 & 154393680 \\
\hline $\mathrm{C}$ & $\mathrm{C}$ & $A$ & rs3778153 & 154393884 \\
\hline $\mathrm{A}$ & $\mathrm{A}$ & $\mathrm{G}$ & rs9478504 & 154395159 \\
\hline $\mathrm{T}$ & $\mathrm{T}$ & $\mathrm{A}$ & rs17209711 & 154396455 \\
\hline $\mathrm{G}$ & $\mathrm{G}$ & $\mathrm{A}$ & rs17275521 & 154396472 \\
\hline $\mathrm{G}$ & $\mathrm{G}$ & $\mathrm{C}$ & rs144155532 & 154398647 \\
\hline $\mathrm{G}$ & $\mathrm{G}$ & A & rs9478505 & 154399992 \\
\hline $\mathrm{A}$ & $\mathrm{A}$ & $\mathrm{G}$ & rs9479755 & 154402414 \\
\hline
\end{tabular}

$=$ major allele $\square=$ minor allele

(b)

Haplotype
REF
\begin{tabular}{|l|l|l|l|l|l|}
\hline ALT & \multicolumn{1}{c}{ Beta } & \multicolumn{1}{c|}{ SE } & P-value \\
\hline 1 & A & B & -0.03 & 0.04 & 0.52 \\
\hline 2 & A & C & 0.23 & 0.04 & $1.63 \times 10^{-10}$ \\
\hline 3 & B & C & 0.26 & 0.05 & $1.68 \times 10^{-7}$ \\
\hline
\end{tabular}

15 Figure 2. Association of major haplotypes for genome-wide significant OPRM1 variants with OA. (a)

16 The 3 major haplotypes for genome-wide significant OPRM1 variants. Haplotype A is the predominant 
17 haplotype (frequency 0.69 among contributing cohorts) and consists of major alleles for all variants.

18 Haplotype B (frequency 0.13 among contributing cohorts) consists of the minor allele for rs 1799971 and the 19 major allele for all other variants. Haplotype $\mathrm{C}$ (frequency $~ 0.16$ among contributing cohorts) consists of the j0 major allele for rs 1799971 and minor allele for all other variants. The cohorts for whom we had the raw data to ¡1 conduct the haplotype analyses were: UHS, VIDUS, ODB, Yale-Penn, CATS and Kreek (Supplementary Table j2 1). (b) Association of OPRM1 haplotypes with $O A$. Haplotype $\mathrm{C}$ is associated with increased risk of $O A$ when ¡3 compared to Haplotype A or Haplotype B, whereas Haplotype B does not have a significant impact on OA j4 relative to Haplotype A. The single variant results using the cohorts contributing to the haplotype analyses j5 were: $r s 1799971$ beta $=-0.058, p=0.135 ;$ rs9478500 beta $=0.205, p=2.43 \times 10^{-9}$. 
medRxiv preprint doi: https://doi.org/10.1101/2021.09.13.21263503; this version posted September 16, 2021. The copyright holder for this preprint (which was not certified by peer review) is the author/funder, who has granted medRxiv a license to display the preprint in perpetuity.

It is made available under a CC-BY-NC-ND 4.0 International license .

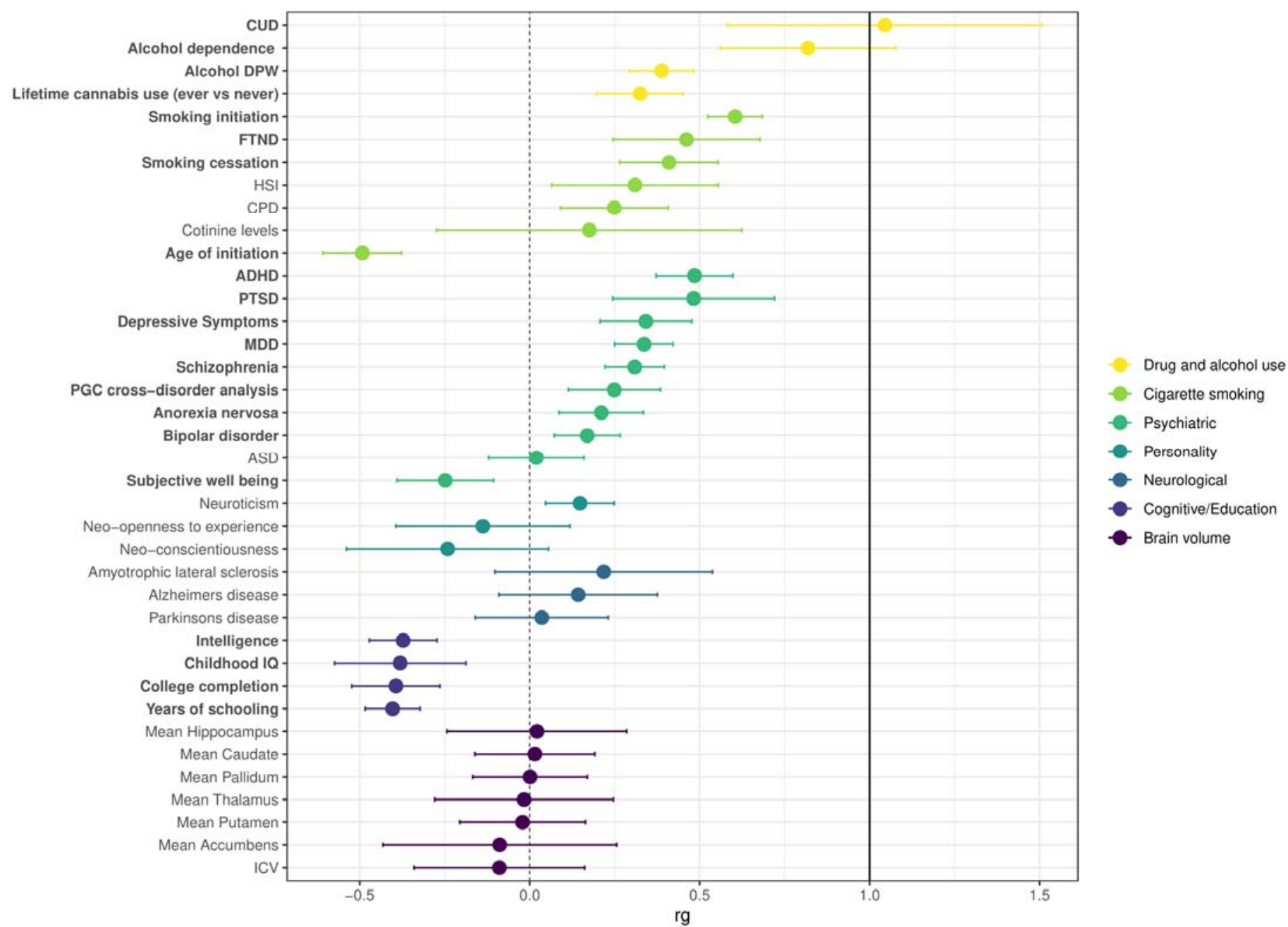

Figure 3. Genetic correlations of opioid addiction (OA) with 38 other brain-related phenotypes.

j9 Correlations were calculated using linkage disequilibrium (LD) score regression with the gSEM OA GWAS meta-analysis results, compared with results made available via LD Hub or study investigators (see

¡1 Supplementary Table 20 for original references). Phenotypes were grouped by disease/trait or measurement category, as indicated by different colorings. Dots indicate the mean values for genetic correlation $\left(r_{\mathrm{g}}\right)$; error bars show the $95 \%$ confidence intervals; the dashed vertical black line corresponds to $r_{\mathrm{g}} \square=\square 0$ (no correlation

j4 with OA), and the solid vertical black line corresponds to $r_{\mathrm{g}} \square=\square 1.0$ (complete correlation with OA). Phenotypes with significant correlation with OA are bolded (1 degree of freedom Chi-square test; Bonferroni adjusted $p$ - 
medRxiv preprint doi: https://doi.org/10.1101/2021.09.13.21263503; this version posted September 16, 2021. The copyright holder for this preprint (which was not certified by peer review) is the author/funder, who has granted medRxiv a license to display the preprint in perpetuity.

It is made available under a CC-BY-NC-ND 4.0 International license .

36 value $<0.05$ after accounting for 38 independent tests). Exact $p$-values are provided in Supplementary Table

37 8).

i8

i9 
medRxiv preprint doi: https://doi.org/10.1101/2021.09.13.21263503; this version posted September 16, 2021. The copyright holder for this preprint (which was not certified by peer review) is the author/funder, who has granted medRxiv a license to display the preprint in perpetuity.

It is made available under a CC-BY-NC-ND 4.0 International license .

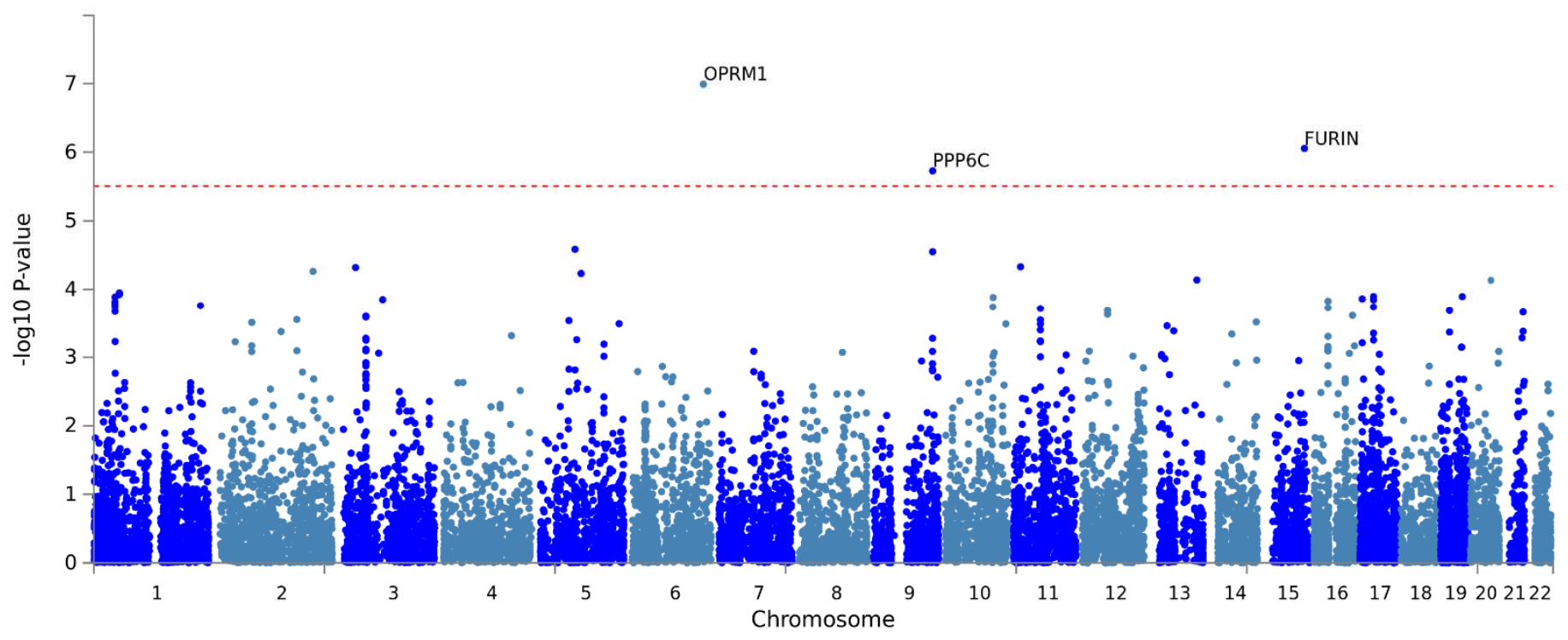

Figure 4. Gene-level Manhattan Plot. GWAS results were summarized at the gene-level using MAGMA.

73 Bonferroni correction was used to correct for multiple comparisons; associations with $\mathrm{P}<3 \times 10^{-6}$ (indicated by

74 horizontal red dotted line) were considered to be genome-wide significant. 
medRxiv preprint doi: https://doi.org/10.1101/2021.09.13.21263503; this version posted September 16, 2021. The copyright holder for this preprint (which was not certified by peer review) is the author/funder, who has granted medRxiv a license to display the preprint in perpetuity.

It is made available under a CC-BY-NC-ND 4.0 International license.
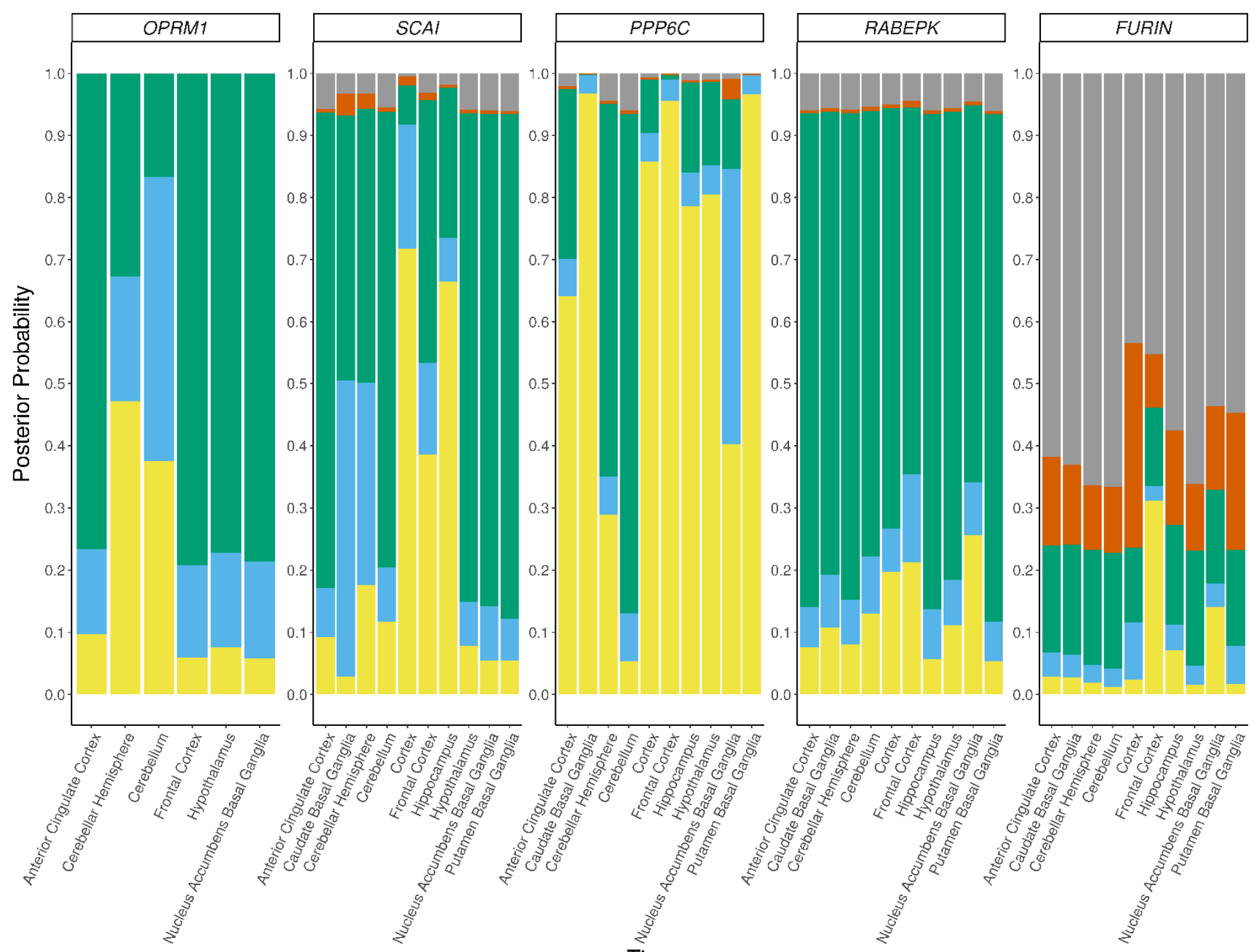

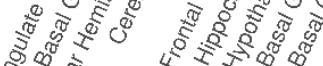
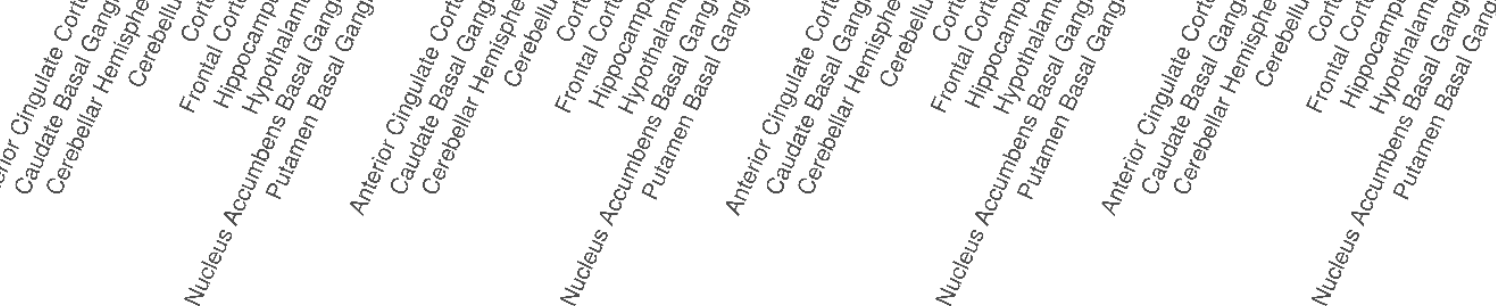

Tissue

Hypothesis

$\mathrm{HO}$ : Neither trait has a genetic association in the region

$\mathrm{H} 1$ : Cis-eQTL results have a genetic association in the region

$\mathrm{H} 2$ : Meta-analysis results have a genetic association in the region
H3: Both traits are associated, but with different causal variants $\mathrm{H} 4$ :Both traits are associated and share a single causal variant

Figure 5. Colocalization of GWAS loci and QTLs for selected genes across $\mathbf{1 0}$ brain tissues. Posterior

78 probabilities of supporting hypotheses regarding the association of each trait with SNPs in a region were

79 calculated using coloc. For OPRM1, SNP-gene cis-eQTL associations were reported in GTEx Analysis v8 for

only 6 of the 10 tissues. 


\section{References}

1. $\quad$ Ahmad, F.B., Rossen, L.M. \& Sutton, P. Provisional drug overdose death counts. (National Center for Health Statistics, 2021).

2. Rudd, R.A., Aleshire, N., Zibbell, J.E. \& Gladden, R.M. Increases in drug and opioid overdose deaths United States, 2000-2014. MMWR Morb Mortal Wkly Rep 64, 1378-82 (2016).

3. National Safety Council. Motor vehicle deaths estimated to have dropped $2 \%$ in 2019. (2020).

4. Substance Abuse and Mental Health Services Administration. Key substance use and mental health indicators in the United States: Results from the 2019 National Survey on Drug Use and Health (HHS Publication No. PEP20-07-01-001, NSDUH Series H-55). (Center for Behavioral Health Statistics and Quality, Substance Abuse and Mental Health Services Administration., Rockville, MD, 2020).

5. Florence, C.S., Zhou, C., Luo, F. \& Xu, L. The economic burden of prescription opioid overdose, abuse, and dependence in the United States, 2013. Med Care 54, 901-6 (2016).

6. Leslie, D.L., Ba, D.M., Agbese, E., Xing, X. \& Liu, G. The economic burden of the opioid epidemic on states: The case of Medicaid. Am J Manag Care 25, S243-S249 (2019).

7. National Academies of Sciences, Engineering, and Medicine. Medications for opioid use disorder save lives. (eds Leshner, A. \& Mancher, M.) (Washington D.C. , 2019).

8. Koob, G.F. \& Volkow, N.D. Neurocircuitry of addiction. Neuropsychopharmacology 35, 217-38 (2010).

9. Kreek, M.J. et al. Opiate addiction and cocaine addiction: underlying molecular neurobiology and genetics. J Clin Invest 122, 3387-93 (2012).

10. Santiago Rivera, O.J., Havens, J.R., Parker, M.A. \& Anthony, J.C. Risk of heroin dependence in newly incident heroin users. JAMA Psychiatry 75, 863-864 (2018).

11. Vowles, K.E. et al. Rates of opioid misuse, abuse, and addiction in chronic pain: A systematic review and data synthesis. Pain 156, 569-76 (2015).

12. Kendler, K.S., Jacobson, K.C., Prescott, C.A. \& Neale, M.C. Specificity of genetic and environmental risk factors for use and abuse/dependence of cannabis, cocaine, hallucinogens, sedatives, stimulants, and opiates in male twins. Am J Psychiatry 160, 687-95 (2003).

13. Goldman, D., Oroszi, G. \& Ducci, F. The genetics of addictions: Uncovering the genes. Nat Rev Genet 6, 521-32 (2005).

14. Gatz, M. et al. Role of genes and environments for explaining Alzheimer disease. Arch Gen Psychiatry 63, 168-74 (2006).

15. Klaver, C.C. et al. Genetic risk of age-related maculopathy. Population-based familial aggregation study. Arch Ophthalmol 116, 1646-51 (1998).

16. Zaitlen, N. et al. Leveraging population admixture to characterize the heritability of complex traits. Nat Genet 46, 1356-62 (2014).

17. Levran, O., Yuferov, V. \& Kreek, M.J. The genetics of the opioid system and specific drug addictions. Hum Genet 131, 823-42 (2012).

18. Hancock, D.B., Markunas, C.A., Bierut, L.J. \& Johnson, E.O. Human genetics of addiction: New insights and future directions. Curr Psychiatry Rep 20, 8 (2018).

19. Crist, R.C., Reiner, B.C. \& Berrettini, W.H. A review of opioid addiction genetics. Curr Opin Psychol 27 , 31-35 (2019).

20. Gelernter, J. \& Polimanti, R. Genetics of substance use disorders in the era of big data. Nat Rev Genet (2021). 
21. Nielsen, D.A. et al. Genotype patterns that contribute to increased risk for or protection from developing heroin addiction. Mol Psychiatry 13, 417-28 (2008).

22. Nielsen, D.A. et al. Genome-wide association study identifies genes that may contribute to risk for developing heroin addiction. Psychiatr Genet 20, 207-14 (2010).

23. Gelernter, J. et al. Genome-wide association study of opioid dependence: multiple associations mapped to calcium and potassium pathways. Biol Psychiatry 76, 66-74 (2014).

24. Nelson, E.C. et al. Evidence of CNIH3 involvement in opioid dependence. Mol Psychiatry 21, 608-14 (2016).

25. Cheng, Z. et al. Genome-wide association study identifies a regulatory variant of RGMA associated with opioid dependence in European Americans. Biol Psychiatry 84, 762-770 (2018).

26. Polimanti, R. et al. Leveraging genome-wide data to investigate differences between opioid use vs. opioid dependence in 41,176 individuals from the Psychiatric Genomics Consortium. Molecular Psychiatry, 1-15 (2020).

27. Zhou, H. et al. Association of OPRM1 functional coding variant with opioid use disorder: A genomewide association study. JAMA Psychiatry (2020).

28. Song, W. et al. Genome-wide association analysis of opioid use disorder: A novel approach using clinical data. Drug Alcohol Depend 217, 108276 (2020).

29. Nelson, E.C. et al. Association of OPRD1 polymorphisms with heroin dependence in a large casecontrol series. Addict Biol 19, 111-21 (2014).

30. Grotzinger, A.D. et al. Genomic structural equation modelling provides insights into the multivariate genetic architecture of complex traits. Nat Hum Behav 3, 513-525 (2019).

31. Liu, M. et al. Association studies of up to 1.2 million individuals yield new insights into the genetic etiology of tobacco and alcohol use. Nat Genet 51, 237-244 (2019).

32. Wootton, R.E. et al. Evidence for causal effects of lifetime smoking on risk for depression and schizophrenia: a Mendelian randomisation study. Psychol Med 50, 2435-2443 (2020).

33. Baselmans, B.M.L. et al. Multivariate genome-wide analyses of the well-being spectrum. Nat Genet 51, 445-451 (2019).

34. Schizophrenia Working Group of the Psychiatric Genomics, C. Biological insights from 108 schizophrenia-associated genetic loci. Nature 511, 421-7 (2014).

35. Periyasamy, S. et al. Association of Schizophrenia Risk With Disordered Niacin Metabolism in an Indian Genome-wide Association Study. JAMA Psychiatry 76, 1026-1034 (2019).

36. Karlsson Linner, R. et al. Genome-wide association analyses of risk tolerance and risky behaviors in over 1 million individuals identify hundreds of loci and shared genetic influences. Nat Genet 51, 245257 (2019).

37. Hancock, D.B. et al. Cis-expression quantitative trait loci mapping reveals replicable associations with heroin addiction in OPRM1. Biol Psychiatry 78, 474-484 (2015).

38. Levran, O., Awolesi, O., Linzy, S., Adelson, M. \& Kreek, M.J. Haplotype block structure of the genomic region of the mu opioid receptor gene. J Hum Genet 56, 147-55 (2011).

39. de Leeuw, C.A., Mooij, J.M., Heskes, T. \& Posthuma, D. MAGMA: generalized gene-set analysis of GWAS data. PLoS Comput Biol 11, e1004219 (2015).

40. Barbeira, A.N. et al. Exploring the phenotypic consequences of tissue specific gene expression variation inferred from GWAS summary statistics. Nat Commun 9, 1825 (2018).

41. Giambartolomei, C. et al. A Bayesian framework for multiple trait colocalization from summary association statistics. Bioinformatics 34, 2538-2545 (2018).

42. Cotto, K.C. et al. DGldb 3.0: a redesign and expansion of the drug-gene interaction database. Nucleic Acids Res 46, D1068-d1073 (2018).

43. Subramanian, A. et al. A Next Generation Connectivity Map: L1000 Platform and the First 1,000,000 Profiles. Cell 171, 1437-1452.e17 (2017). 
44. Sheils, T.K. et al. TCRD and Pharos 2021: mining the human proteome for disease biology. Nucleic Acids Res 49, D1334-D1346 (2021).

45. Mitsopoulos, C. et al. canSAR: update to the cancer translational research and drug discovery knowledgebase. Nucleic Acids Res 49, D1074-D1082 (2021).

46. Gelernter, J. et al. Genome-wide association study of opioid dependence: Multiple associations mapped to calcium and potassium pathways. Biol Psychiatry (2013).

47. Sanchez-Roige, S. et al. Genome-wide association study of problematic opioid prescription use in 132,113 23andMe research participants of European ancestry. medRxiv, 2021.06.03.21258260 (2021).

48. Zhang, $\mathrm{H}$. et al. Association between two mu-opioid receptor gene (OPRM1) haplotype blocks and drug or alcohol dependence. Hum Mol Genet 15, 807-19 (2006).

49. Levran, O. et al. Genetic susceptibility to heroin addiction: a candidate gene association study. Genes Brain Behav 7, 720-9 (2008).

50. McCoy, M.T., Jayanthi, S. \& Cadet, J.L. Potassium Channels and Their Potential Roles in Substance Use Disorders. Int J Mol Sci 22(2021).

51. Schwantes-An, T.H. et al. Association of the OPRM1 Variant rs1799971 (A118G) with Non-Specific Liability to Substance Dependence in a Collaborative de novo Meta-Analysis of European-Ancestry Cohorts. Behav Genet 46, 151-69 (2016).

52. Levran, O. \& Kreek, M.J. Population-specific genetic background for the OPRM1 variant rs1799971 $(118 \mathrm{~A}>\mathrm{G})$ : implications for genomic medicine and functional analysis. Mol Psychiatry (2020).

53. Rex, E.B. et al. Identification of RanBP 9/10 as interacting partners for protein kinase C (PKC) gamma/delta and the D1 dopamine receptor: regulation of PKC-mediated receptor phosphorylation. Mol Pharmacol 78, 69-80 (2010).

54. Polimanti, R. et al. Multi-environment gene interactions linked to the interplay between polysubstance dependence and suicidality. Translational Psychiatry 11, 34 (2021).

55. Bult, C.J. et al. Mouse Genome Database (MGD) 2019. Nucleic Acids Res 47, D801-D806 (2019).

56. Zarrinmayeh, H.A.-O. \& Territo, P.R. Purinergic Receptors of the Central Nervous System: Biology, PET Ligands, and Their Applications. (2020).

57. Zhou, H. et al. GWAS including 82,707 subjects identifies functional coding variant in OPRM1 gene associated with opioid use disorder. (2019).

58. Smith, A.H. et al. Genome-wide association study of therapeutic opioid dosing identifies a novel locus upstream of OPRM1. Mol Psychiatry 22, 346-352 (2017).

59. Ghoussaini, M. et al. Open Targets Genetics: systematic identification of trait-associated genes using large-scale genetics and functional genomics. Nucleic Acids Res 49, D1311-D1320 (2021).

60. Ochoa, D. et al. Open Targets Platform: supporting systematic drug-target identification and prioritisation. Nucleic Acids Res 49, D1302-D1310 (2021).

61. Marquez-Luna, C., Loh, P.R., South Asian Type 2 Diabetes, C., Consortium, S.T.D. \& Price, A.L. Multiethnic polygenic risk scores improve risk prediction in diverse populations. Genet Epidemiol 41, 811-823 (2017).

62. Holland, D. et al. Beyond SNP heritability: Polygenicity and discoverability of phenotypes estimated with a univariate Gaussian mixture model. PLoS Genet 16, e1008612 (2020).

63. Pritchard, J.K., Stephens, M. \& Donnelly, P. Inference of population structure using multilocus genotype data. Genetics 155, 945-959 (2000).

64. Das, S. et al. Next-generation genotype imputation service and methods. Nat Genet 48, 1284-1287 (2016).

65. Delaneau, O., Howie, B., Cox, A.J., Zagury, J.F. \& Marchini, J. Haplotype estimation using sequencing reads. Am J Hum Genet 93, 687-96 (2013).

66. Kong, A. et al. Detection of sharing by descent, long-range phasing and haplotype imputation. Nature Genetics 40, 1068-1075 (2008). 
medRxiv preprint doi: https://doi.org/10.1101/2021.09.13.21263503; this version posted September 16, 2021. The copyright holder for this preprint (which was not certified by peer review) is the author/funder, who has granted medRxiv a license to display the preprint in perpetuity.

It is made available under a CC-BY-NC-ND 4.0 International license .

67. Zhan, X., Hu, Y., Li, B., Abecasis, G.R. \& Liu, D.J. RVTESTS: an efficient and comprehensive tool for rare variant association analysis using sequence data. Bioinformatics 32, 1423-6 (2016).

68. Price, A.L. et al. The impact of divergence time on the nature of population structure: an example from Iceland. PLoS Genet 5, e1000505 (2009).

69. Bulik-Sullivan, B.K. et al. LD Score regression distinguishes confounding from polygenicity in genomewide association studies. Nat Genet 47, 291-5 (2015).

70. Willer, C.J., Li, Y. \& Abecasis, G.R. METAL: fast and efficient meta-analysis of genomewide association scans. Bioinformatics 26, 2190-1 (2010).

71. Watanabe, K., Taskesen, E., van Bochoven, A. \& Posthuma, D. Functional mapping and annotation of genetic associations with FUMA. Nat Commun 8, 1826 (2017).

72. Urbut, S.M., Wang, G., Carbonetto, P. \& Stephens, M. Flexible statistical methods for estimating and testing effects in genomic studies with multiple conditions. Nature Genetics 51, 187-195 (2019).

73. Wen, X., Lee, Y., Luca, F. \& Pique-Regi, R. Efficient Integrative Multi-SNP Association Analysis via Deterministic Approximation of Posteriors. Am J Hum Genet 98, 1114-1129 (2016).

74. Consortium, T.G. The Genotype-Tissue Expression (GTEx) pilot analysis: Multitissue gene regulation in humans. Science 348, 648-660 (2015).

75. Barbeira, A.N. \& Im, H.K. GWAS summary statistics imputation support data and integration with PrediXcan MASHR. (ed. Zenodo) (2019).

76. Giambartolomei, C. et al. Bayesian test for colocalisation between pairs of genetic association studies using summary statistics. PLoS Genet 10, e1004383 (2014). 